\title{
The Character and Causes of Elevation-Dependent Warming in High-Resolution Simulations of Rocky Mountain Climate Change $\mathscr{A}$
}

\author{
JUSTIN R. MindER AND THEODORE W. LETCHER \\ University at Albany, State University of New York, Albany, New York \\ Changhai LiU \\ National Center for Atmospheric Research, Boulder, Colorado
}

(Manuscript received 17 May 2017, in final form 28 November 2017)

\begin{abstract}
The character and causes of elevation-dependent warming (EDW) of surface temperatures are examined in a suite of high-resolution $(\Delta x \leq 12 \mathrm{~km})$ regional climate model (RCM) simulations of climate change over the Rocky Mountains using the Weather Research and Forecasting Model. A clear EDW signal is found over the region, with warming enhanced in certain elevation bands by as much as $2^{\circ} \mathrm{C}$. During some months warming maximizes at middle elevations, whereas during others it increases monotonically with elevation or is nearly independent of elevation. Simulated EDW is primarily caused by the snow albedo feedback (SAF). Warming maximizes in regions of maximum snow loss and albedo reduction. The role of the SAF is confirmed by sensitivity experiments wherein the SAF is artificially suppressed. The elevation dependence of freetropospheric warming appears to play a secondary role in shaping EDW. No evidence is found for a contribution from elevation-dependent water vapor feedbacks. Sensitivity experiments show that EDW depends strongly on certain aspects of RCM configuration. Simulations using 4- and 12-km horizontal grid spacings show similar EDW signals, but substantial differences are found when using a grid spacing of $36 \mathrm{~km}$ due to the influence of terrain resolution on snow cover and the SAF. Simulations using the Noah and Noah-MP land surface models (LSMs) exhibit large differences in EDW. These are caused by differences between LSMs in their representations of midelevation snow extent and in their parameterization of subpixel fractional snow cover. These lead to albedo differences that act to modulate the simulated SAF and its effect on EDW.
\end{abstract}

\section{Introduction}

What patterns of warming can be expected over mountains as they experience the effects of anthropogenic climate change? This question is scientifically compelling, since the answer is not obvious and is determined by a range of physical processes operating at a range of spatial and temporal scales. It is also of practical importance, since the magnitude and character of climate warming over mountains will shape climate impacts on ecosystems, water resources, and natural hazards (e.g., Beniston 2003; Viviroli et al. 2011; Gottfried et al. 2012). A variety of observational and modeling studies have argued that the climate warming

Supplemental information related to this paper is available at the Journals Online website: https://doi.org/10.1175/JCLI-D-17-0321.s1.

Corresponding author: Justin R. Minder, jminder@albany.edu over mountains has had, or will have, a systematic dependence on elevation, with certain elevation ranges experiencing enhanced warming relative to others. This phenomenon is referred to as elevation-dependent warming (EDW; e.g., Pepin et al. 2015).

\section{a. Evidence of EDW}

A recent review of the literature by Pepin et al. (2015) concluded that "a majority of studies suggest that warming is more rapid at higher elevations but there are a number of studies that show either no relationship or a more complex situation" (p. 424). Sources of variability between studies in the significance and structure of EDW include the diversity of geographic regions studied (including many different mountain ranges in different climate zones), time periods considered (including different past and future periods), and methodologies applied (including different observational datasets and modeling frameworks). 
Observational studies of EDW face challenges associated with the lack of climate records over mountainous terrain that are long-term and homogeneous (e.g., devoid of nonclimatic artifacts, such as might be caused by changes in measurement practices). These studies show mixed results depending on the region, season, and dataset considered (Pepin et al. 2015). Global station data do not show a simple monotonic increase in warming with elevation (Pepin and Lundquist 2008). While observations appear to show significant EDW over many regions (e.g., Liu et al. 2009; Wang et al. 2014; Vuille et al. 2015), results can be highly sensitive to the dataset used. For instance, over the Tibetan Plateau and the U.S. Rocky Mountains, some homogenized datasets, where artifacts associated with changes in measurement practices have been removed, do not reproduce the EDW found in other studies of the same regions (You et al. 2010; Oyler et al. 2015).

Numerical climate models have also been useful for the study of EDW, as model output can overcome some limitations of observational datasets, represent future climate scenarios, and enable diagnosis of physical mechanisms. Numerous studies have investigated EDW in global climate models (GCMs) and nearly all of these document a clear EDW signal, with warming either increasing monotonically with elevation or maximizing at some intermediate elevation (e.g., Fyfe and Flato 1999; Bradley et al. 2004; Liu et al. 2009; Rangwala et al. 2010, 2013; Yan et al. 2016; Rangwala et al. 2016; Palazzi et al. 2017). However, caution must be used in interpretation of GCM-simulated warming over mountains, because terrain features and their important influences on regional climate are often poorly resolved in coarseresolution GCMs (e.g., Salathé et al. 2008).

Regional climate models (RCMs), run at a higher spatial resolution over limited domains, can better represent some of these important terrain interactions as compared to GCMs. Various studies have used RCMs to investigate patterns of climate warming over mountainous terrain, including the Tibetan Plateau (Guo et al. 2016), the European Alps (Giorgi et al. 1997; Im et al. 2010; Kotlarski et al. 2012, 2015; Winter et al. 2017), and the mountains of the western United States (Salathé et al. 2008; Rangwala et al. 2012; Letcher and Minder 2015; Walton et al. 2015; Minder et al. 2016; Rupp et al. 2017; Walton et al. 2017). All of these RCM studies show evidence of EDW under future climate change, with warming either increasing with elevation or maximizing at midelevations. Simulations with variableresolution GCMs (VRGCMs), with enhanced resolution over the mountains of the western United States, also show similar results (Rhoades et al. 2018). However, the sensitivity of RCM- and VRGCM-simulated
EDW to model configuration is largely unknown. For instance, the above-listed studies use horizontal grid spacings ranging from 4 to $50 \mathrm{~km}$, and thus resolve the terrain and its effect on climate to varying degrees. The impact of such differences in resolution, or other differences in model forcing or parameterization schemes, have not been evaluated and may represent an important source of uncertainty.

\section{b. Mechanisms of EDW}

A variety of physical mechanisms have been proposed to explain EDW [see Pepin et al. (2015) for a detailed summary]. The most common mechanism cited is the snow albedo feedback (SAF; e.g., Giorgi et al. 1997; Fyfe and Flato 1999; Pepin and Lundquist 2008; Liu et al. 2009; Rangwala et al. 2010; Kotlarski et al. 2015; Yan et al. 2016; Rangwala et al. 2016; Palazzi et al. 2017; Guo et al. 2016; Winter et al. 2017; Rupp et al. 2017; Walton et al. 2017; Rhoades et al. 2018). Under climate change, reductions in mountain snow cover often depend strongly on elevation and maximize near the lowelevation margin of the snowpack. This leads to elevation-dependent reductions in surface albedo and increases in absorbed solar radiation that can lead to elevation-dependent amplification of warming via the SAF. This mechanism is supported by observations of warming maxima occurring at temperatures near the freezing point of water (e.g., Pepin and Lundquist 2008) and by strong correlations between simulated patterns of warming and snow cover/albedo reductions.

Spatial variations in free tropospheric warming may also contribute to EDW. In many parts of the world, climate warming is expected to vary with elevation in the troposphere, and several modeling studies have indicated that such variations may contribute to EDW (Bradley et al. 2004; Kotlarski et al. 2012; Rangwala et al. 2016; Rupp et al. 2017). Furthermore, spatial variations in free tropospheric warming associated with land-sea contrasts may influence EDW in regions where different elevation bands experience different exposure to marine air (e.g., Kotlarski et al. 2012; Vuille et al. 2015; Walton et al. 2015).

An elevation-dependent longwave water vapor feedback (WVF) has also been hypothesized as a potentially important contributor to EDW (Rangwala et al. 2009, 2010; Rangwala 2013; Rangwala et al. 2016; Palazzi et al. 2017). According to this hypothesis, increases in nearsurface specific humidity expected under climate change lead to larger increases in surface downwelling longwave radiation and subsequently larger warming, over higher terrain where the overlying atmosphere contains less water vapor and water vapor absorption bands are undersaturated. Statistical relationships between warming, 
fractional changes in water vapor, and surface downwelling longwave radiation have been offered as support for this mechanism.

We will primarily discuss the above three candidate mechanisms in this study. However, other potential mechanisms influencing EDW include elevationdependent variations in cloud feedbacks (Liu et al. 2009; Yan et al. 2016), aerosol radiative forcing (Rangwala et al. 2010; Zeng et al. 2015), and vegetation changes (Jiang et al. 2011).

\section{c. EDW over the Rockies}

This study uses high-resolution RCM simulations to characterize EDW and its causes over the Colorado Rocky Mountains. Observational evidence of EDW in this region is equivocal. Work by Diaz and Eischeid (2007) used a gridded product based on station observations (PRISM; Daly et al. 2008) to analyze climate trends over this region from 1979 to 2006 and found substantial increases in warming with elevation. However, subsequent work by Oyler et al. (2015) revealed that temperature trends from PRISM suffered from systematic positive biases at high elevations, due to inhomogeneities in the underlying station data. When these were corrected, no statistically significant EDW was found over the mountains of the western United States as a whole (Oyler et al. 2015).

Simulations of future climate change show a clearer indication of EDW over the Rockies. Analysis of a GCM simulation of climate change by Fyfe and Flato (1999) indicated large increases in warming with elevation during winter and spring caused by the SAF. More recent studies using RCMs to explore the spatial variability of future climate change over the Rockies also suggest important roles for the SAF (Rangwala et al. 2012; Letcher and Minder 2015; Minder et al. 2016) as well as changes in soil moisture and partitioning of energy between turbulent surface fluxes (Rangwala et al. 2012). The more pronounced EDW signal in models relative to observations may be due, in part, to the focus of model studies on aggressive greenhouse gas emissions scenarios and mid- or late-twenty-first-century periods such that the forced response to anthropogenic climate forcing is large, allowing the EDW signal to emerge from the noise of internal climate variability (e.g., Fyfe and Flato 1999; Kotlarski et al. 2012). However, comparisons of different high-resolution RCM simulations indicate that the pattern of climate warming over the Rockies may depend strongly on aspects of model configuration including horizontal resolution (Letcher and Minder 2015) and choice of land surface model (Minder et al. 2016).

\section{d. Goals and outline}

This study aims to better document the characteristics and physical causes of EDW over the Rocky Mountains in high-resolution RCM simulations by addressing the following questions:

- What is the spatial structure and seasonality of simulated EDW over the Rockies?

- What is the role of the SAF in shaping EDW over the Rockies? Do other mechanisms, such as elevationdependent WVFs and free-tropospheric warming patterns, also contribute to EDW?

- How does simulated EDW depend on model configuration, specifically grid resolution and land surface model choice?

Section 2 describes the RCM simulations investigated in this study. Section 3 characterizes the structure and seasonality of EDW in a high-resolution RCM simulation and its dependence on model horizontal resolution. Section 4 diagnoses the mechanisms responsible for the simulated EDW. Section 5 explores the sensitivity of EDW to the parameterization of land surface processes. Section 6 summarizes and concludes.

\section{Methods}

This study investigates EDW in two sets of highresolution RCM experiments over a domain centered on the tallest portion of the Rocky Mountains of the western United States. Figure 1 shows the computational domain used for both of these experiments as well as a smaller domain used for analysis of EDW. This analysis region includes complex topography with a variety of major and minor mountain ranges, valleys, basins, and elevated plateaus (Fig. 1a). The highest mountain peaks exceed $4 \mathrm{~km}$ MSL. Figures $1 \mathrm{~d}$ and $1 \mathrm{e}$ show that low-elevation land cover is mostly a mixture of shrublands, grasslands, and cropland, while midelevation mountain slopes are predominately covered by evergreen needleleaf forests, and the highest elevations are mostly alpine tundra (classified as grassland and shrubland in Figs. 1d,e).

\section{a. High-resolution simulations}

We first analyze EDW in the high-resolution RCM experiments presented by Rasmussen et al. (2014). Since these were focused on the climate of the headwaters region of the Colorado River, we refer to them as the Headwaters (HW) experiments. They were run using version 3.1.1 of the Advanced Research Weather Research and Forecasting (WRF) Model (Skamarock et al. 2008) with 4-km horizontal grid spacing. These and 

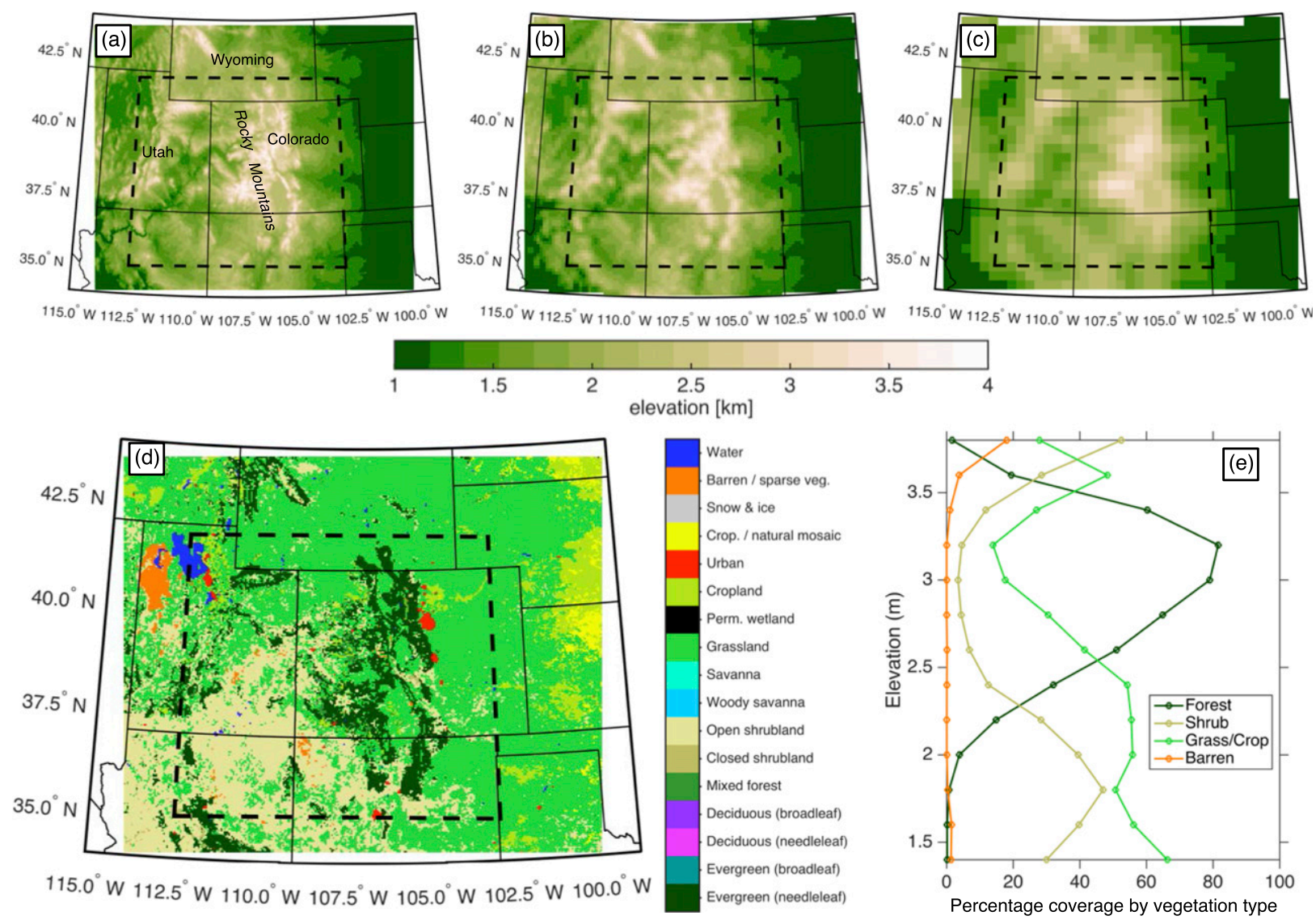

FIG. 1. Attributes of the computational and analysis domains used in WRF simulations. The terrain elevation for the full computational domain (shading) is shown for the three resolutions of the HW simulations: (a) $\Delta x=4 \mathrm{~km}$, (b) $\Delta x=12 \mathrm{~km}$, and (c) $\Delta x=36 \mathrm{~km}$. (d) The dominant vegetation type classifications (shaded) from the grids used to force the $\Delta x=4 \mathrm{~km}$ simulations. (e) The general distribution of vegetation types with elevation within the analysis domain of the $\Delta x=4 \mathrm{~km}$ simulations by grouping the dominant vegetation types into four broad categories (as indicated in legend). In (a)-(d), state boundaries are shown with thin black lines, and the analysis domain used is outlined with a thick dashed line. Selected states are labeled in (a).

other details of model configuration are summarized in Table 1. Configuration choices were guided by the results of experiments that characterized how simulated snowpack and snowfall depend on model grid spacing and parameterization choices (Ikeda et al. 2010; Barlage et al. 2010; Liu et al. 2011). A more complete accounting of model configuration and performance can be found in Rasmussen et al. (2014).

Since this study focuses on near-surface warming, which is in part modulated by the SAF, the parameterization of surface processes and snow cover evolution are particularly important. In the HW experiments, these processes were treated with interactive coupling to the Noah land surface model (LSM; Chen and Dudhia 2001; Ek et al. 2003), including the improvements to snowpack physics described in Barlage et al. (2010). Noah uses a single soil-snow-vegetation blended layer when calculating surface fluxes. Surface albedo of a model grid cell is calculated as a weighted average of a background snow-free albedo and the snow albedo, weighted by the subgrid fractional snow-covered area $f_{\mathrm{SCA}}$. An empirical function is used to parameterize $f_{\mathrm{SCA}}$ based on snow water equivalent (SWE) and vegetation type. No explicit representation of canopy-snowradiation interactions is included.

A control simulation of the historical climate (HWCTRL) was run for the period October 2000-08, forced by reanalysis lateral boundary conditions (BCs). This time period samples years with typical and anomalously high/low temperatures, precipitation, and snowpack conditions. A second experimental climate change simulation (HW-PGW) was run for the same period using the pseudo-global warming (PGW) approach (e.g., Schär et al. 1996; Im et al. 2010; Rasmussen et al. 2011, 2014; Liu et al. 2017). This simulation uses the same reanalysis BCs from the CTRL simulation, but with the lateral BCs perturbed by the addition of seasonally and spatially varying changes taken 
TABLE 1. Summary of WRF model configuration used for the two sets of simulations presented. Configuration options listed in square brackets apply only to certain experiments, as indicated.

\begin{tabular}{|c|c|c|}
\hline & HW & SENS \\
\hline WRF-ARW version & 3.1.1 & 3.7 \\
\hline Horizontal grid spacing & 4 km [HW-12: 12 km, HW-36: 36 km] & $12 \mathrm{~km}$ \\
\hline Time step & $20 \mathrm{~s}$ & $60 \mathrm{~s}$ \\
\hline LSM & Noah (Chen and Dudhia 2001; Ek et al. 2003) & Noah [SENS-NMP: Noah-MP (Niu et al. 2011)] \\
\hline Reanalysis BCs & \multicolumn{2}{|c|}{ NARR (Mesinger et al. 2006) } \\
\hline Microphysics & \multicolumn{2}{|c|}{ Thompson (Thompson et al. 2008) } \\
\hline Radiation & \multicolumn{2}{|c|}{ CAM (Collins et al. 2006) } \\
\hline Planetary boundary layer & \multicolumn{2}{|c|}{ Yonsei University (Hong et al. 2006) } \\
\hline Cumulus convection & Explicit [HW-12, HW-36: Betts-Miller-Janjić] & Betts-Miller-Janjić (Janjić 1994) \\
\hline PGW perturbation $(\mathrm{GCM})$ & CCSM3 ensemble mean (CMIP3) & Multimodel mean (19 GCMs, CMIP5) \\
\hline PGW perturbation (scenario) & SRES A2 & RCP8.5 \\
\hline PGW perturbation (time period) & 2045-55 minus 1995-2005 & 2071-2100 minus 1976-2005 \\
\hline
\end{tabular}

from the mid-twenty-first-century climate response of the CCSM3 GCM to anthropogenic climate change (CMIP3 A2 forcing) as summarized in Table 1 and detailed in Rasmussen et al. (2011, 2014). The annual average PGW perturbations over the computational domain include a near-surface warming of about $2^{\circ} \mathrm{C}$, an approximately $14 \%$ increase in specific humidity, and only small changes $(<1 \%)$ in relative humidity, which are similar to the AR4 multimodel mean changes (Rasmussen et al. 2011). There is some seasonal variation in these perturbations, with PGW BC warming maximizing in January-March at about $3^{\circ} \mathrm{C}$ (Letcher and Minder 2015).

The difference between results from the two simulations (HW-PGW - HW-CTRL) is used to quantify the regional response to the large-scale thermodynamic changes associated with anthropogenic global climate change in the absence of complicating changes in largescale circulation. Since the same large-scale circulation anomalies are prescribed in the BCs of both simulations, this difference is dominated by the forced response to a shift in thermodynamic climate, with minimal contribution from large-scale internal climate variability. This allows for a meaningful characterization of the response to large-scale thermodynamic climate change using a relatively small number of years. These simulations were also repeated with coarser horizontal grid spacings of 12 and $36 \mathrm{~km}$ (HW-12 and HW-36; terrain shown in Figs. 1b,c), and we use results from these simulations to quantify the sensitivity of EDW to model resolution. We limit our analysis of all simulations to the 7-yr period of October 2001-08, omitting the first year of the simulation in order to allow the LSM to equilibrate to the perturbed climate.

Rasmussen et al. (2014) showed that under climate change these simulations produce modest increases in wintertime precipitation and decreases in summer rainfall. They also exhibit a shift of cold season precipitation from snow to rain. During spring and summer, substantial elevation-dependent changes in surface snow cover and SWE are found, with the largest reductions occurring near the low-elevation margin of the seasonal snowpack where temperatures are close to freezing in the control climate. During March-April there is a large loss of snow over the midelevations $(2-3 \mathrm{~km})$ and modest increases over the highest terrain, whereas during June-July snow loss maximizes over the highest terrain (Rasmussen et al. 2014; Letcher and Minder 2015).

\section{b. Sensitivity experiments}

To further understand the processes controlling EDW and the sensitivity of EDW to model configuration we conduct additional sensitivity (SENS) experiments using the same domain and spanning the same time period as the HW experiments, but with a more recent version of WRF (v3.7). The configuration of these experiments is summarized in Table 1 . To save computational expense, a horizontal grid spacing of $12 \mathrm{~km}$ is employed, which, based on the results shown in section 3 , is expected to produce EDW similar to that with 4-km grid spacing.

The control simulations (SENS-CTRL) use the same reanalysis BCs as HW-CTRL. However, for the PGW simulations (SENS-PGW), the perturbation applied is the average end-of-twenty-first-century climate response from an ensemble of 19 CMIP5 GCMs subject to RCP8.5 forcing [following Liu et al. (2017), with details summarized in Table 1]. The specific GCMs were selected based on their favorable performance in reproducing the observed North American climate (Liu et al. 2017). This perturbation is larger than that applied to the HW-PGW experiment, due largely to its focus on late-century changes. It is also more representative of the robust aspects of global climate change projections, due to its incorporation of results from multiple distinct GCMs, which helps to emphasize areas of model agreement. 
We also characterize EDW over our analysis region in the GCMs used to generate the PGW perturbations. To do so, we consider one ensemble member from each of the 19 GCMs. We regrid the monthly average nearsurface temperatures and terrain heights from each GCM to a common $1^{\circ}$ latitude-longitude grid and calculate temperature changes across the same time periods as used to generate the PGW perturbations (Table 1). These changes are binned by each GCM's terrain elevation and compared with the results of the WRF SENS experiments.

To quantify the role of the SAF in EDW, we conduct an additional experiment wherein we repeat the SENSPGW simulation but artificially suppress the SAF. In this "fixed albedo" simulation (SENS-FA) snow cover is allowed to evolve freely but the spatially and seasonally varying values of surface albedo are prescribed to be the same as in the SENS-CTRL simulation. The difference between the perturbed climate with and without albedo changes (SENS-PGW - SENS-FA) quantifies the impact of the SAF. A similar approach has been used to quantify the SAF in GCMs (e.g., Hall 2004).

We also investigate the sensitivity of EDW to the parameterization of land surface processes by repeating the control and perturbed simulations using the Noah-MP LSM (Niu and Yang 2007; Niu et al. 2011). As compared to Noah, Noah-MP has a more sophisticated representation of snowpack physics and snow-vegetation-radiation interactions, which may be important due to the role that vegetation can play in masking the SAF (e.g., Loranty et al. 2014; Thackeray et al. 2015; Wang et al. 2016). It outperforms Noah in its representation of SWE, air temperature, and surface energy partitioning over our study region (Fei Chen et al. 2014; Feng Chen et al. 2014). One key difference between the LSMs is that Noah-MP's representation of $f_{\mathrm{SCA}}$, and consequently surface albedo, considers the physical processes whereby snow accumulates and is removed from the vegetation canopy. This and other differences between Noah and Noah-MP appear to strongly affect the simulated surface albedo over the Rockies and to modulate the strength of the SAF (Minder et al. 2016). Comparisons of these simulations (SENS-NMP-CTRL and SENS-NMP-PGW) with the Noah-based simulations provide an example of how uncertainties in the treatment of land surface processes can affect the simulation of EDW.

\section{c. Evaluation against satellite-estimated snow cover}

To evaluate the realism of the simulated snow cover from the SENS experiments we compare the CTRL simulations run using the LSMs Noah (SENS-CTRL) and Noah-MP (SENS-NMP-CTRL) against satellite-based estimates of snow cover. Output from the WRF simulations are averaged over the analysis domain and the 7 -yr analysis period for 16-day intervals. We focus on evaluating $f_{\mathrm{SCA}}$ because it directly influences surface albedo in both LSMs and can be estimated by satellite. Modeled $f_{\mathrm{SCA}}$ is compared against retrievals from the Moderate Resolution Imaging Spectroradiometer (MODIS) Snow-Covered Area and Grain size (MODSCAG) algorithm (Painter et al. 2009) following the methods of Minder et al. (2016).

\section{The structure, seasonality, and resolution dependence of EDW}

The elevation dependence of climate warming from the HW experiments is shown in Fig. 2. For each month the 7-yr average change (HW-PGW - HW-CTRL) in 2-m air temperature $\Delta T$ is plotted, binned by terrain elevation in 200-m bins. Results are shown for all three horizontal grid spacings used. There is warming in all months, varying seasonally and maximizing in spring. Interannual and spatial variability of the warming (shown with shading and whiskers in Fig. 2 for the 12-km simulation) is substantial during January-May and very small in July-October. The structure of simulated EDW depends on season. From August-December EDW variations are small, with $\Delta T$ values differing by less than $0.40^{\circ} \mathrm{C}$ between elevation bins. In contrast, during June and July there is a nearly monotonic increase in $\Delta T$ with increasing elevation, yielding EDW variations that reach $1.0^{\circ} \mathrm{C}$ in June. However, a different pattern is found during March-April when $\Delta T$ exhibits a distinct maximum at midelevations, where it exceeds lowelevation warming by up to $1.5^{\circ} \mathrm{C}$.

EDW is found at all three horizontal resolutions considered, with similar structures. The $4-$ and $12-\mathrm{km}$ simulations agree very well, with differences between them exceeding $0.20^{\circ} \mathrm{C}$ only in the highest-elevation bins during May-June. Larger differences, up to $0.65^{\circ} \mathrm{C}$, are seen when comparing the $4-$ and $36-\mathrm{km}$ simulations, particularly in January-June when EDW is pronounced.

To investigate the role of the SAF in EDW, changes in surface albedo binned by elevation are plotted in Fig. 3 . Widespread reductions in albedo are found throughout the October-June period. These reductions are entirely caused by a loss of snow cover, since land use and vegetation properties are held fixed between the CTRL and PGW simulations. Accordingly, the elevation dependence of albedo change closely follows the pattern of SWE and snow cover loss, with the largest changes in spring and early summer near the margin of the snowpack, maximizing first at midelevations and then at high elevations (Rasmussen et al. 2014; Letcher and Minder 
Jan.
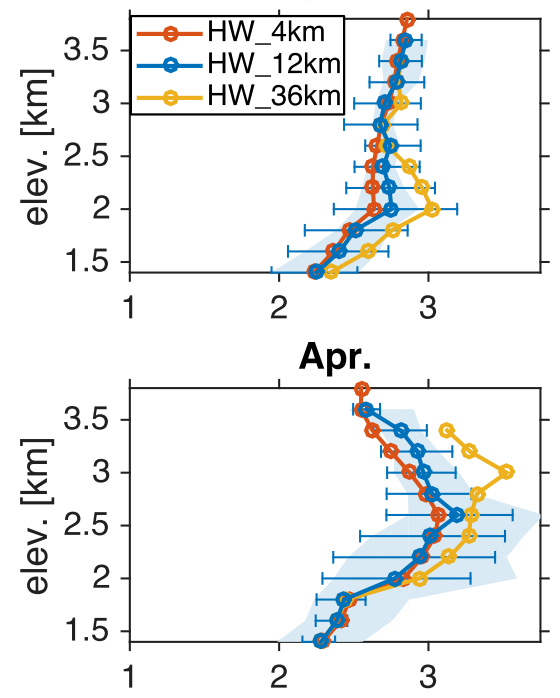

Jul.
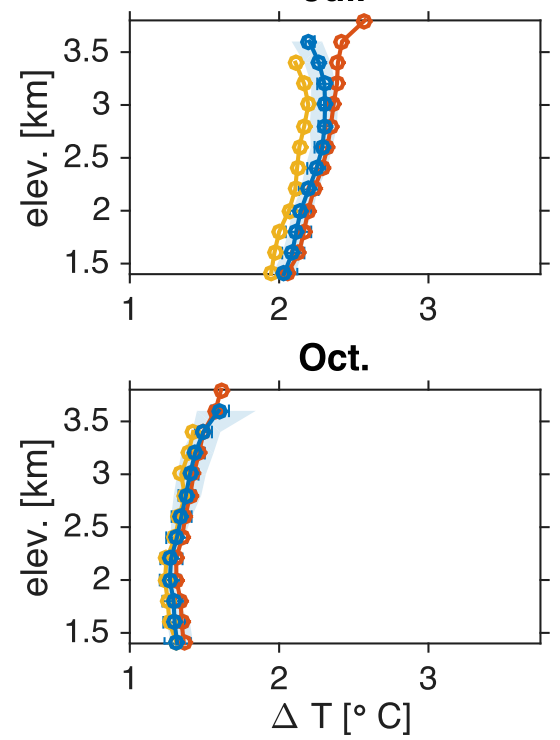

Feb.
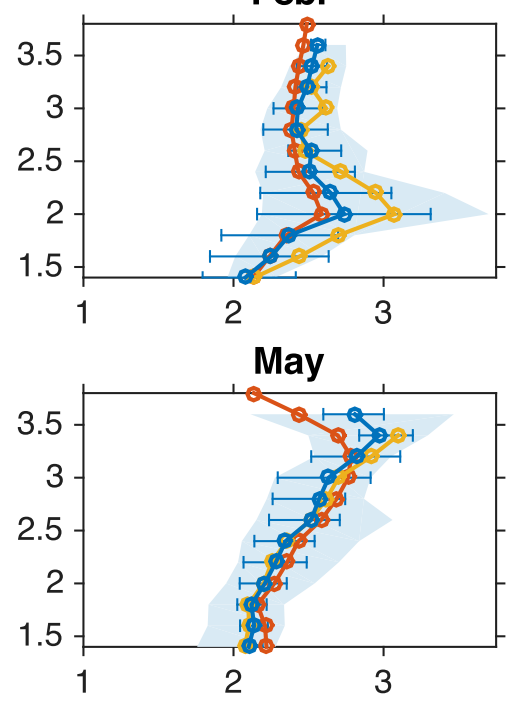

Aug.

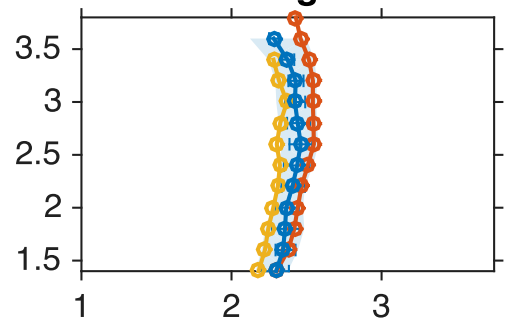

Nov.

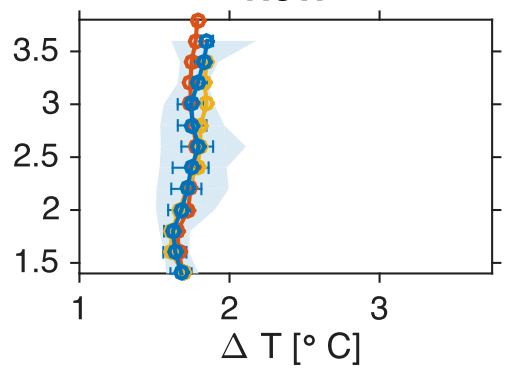

Mar.

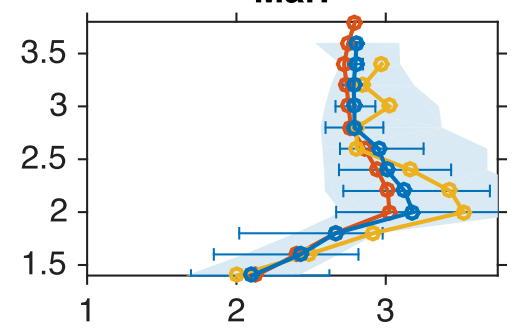

Jun.

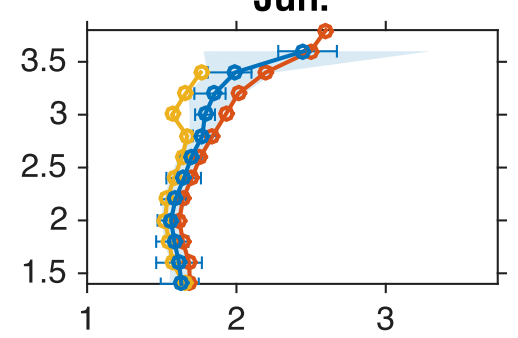

Sept.

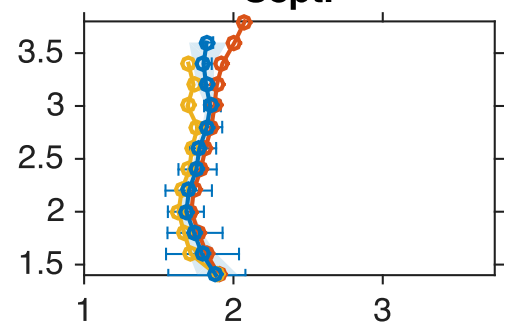

Dec.

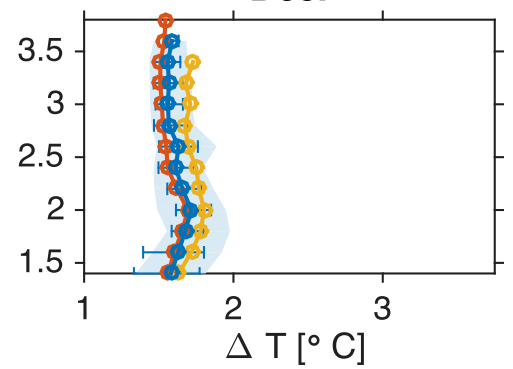

FIG. 2. Change in 7-yr average monthly mean 2-m temperature between HW simulations (PGW - CTRL) $\Delta T$ binned by terrain elevation and averaged over the analysis domain denoted in Fig. 1. Results are shown for experiments run with three different horizontal grid spacings $(\Delta x=4,12,36 \mathrm{~km})$ as indicated by key. Blue shading shows the full interannual range of changes in the $\Delta x=12 \mathrm{~km}$ simulation over the years analyzed. Horizontal whiskers show the interquartile range of the spatial variability in the multiyear average within each bin.

2015). There is a generally good correspondence between the elevation dependence of warming and albedo reduction, consistent with the hypothesis that the SAF exerts strong control on EDW. The strength of the SAF is determined both by the amount of albedo reduction and by the amount of incoming solar radiation, such that over the Rockies albedo reductions in March-June are much more effective at enhancing warming than reductions occurring in November-January (Letcher and Minder 2015). This helps to explain the relatively muted EDW response to albedo changes in November-January.
The SAF also appears to largely explain differences in EDW that arise between simulations with differing horizontal grid spacings. In comparing the 36- and 4-km simulations, elevation bands with enhanced or reduced warming are also associated with similarly enhanced or reduced magnitudes of albedo change (Figs. 2 and 3). The structure and seasonality of these differences can be largely understood in terms of the effect that grid spacing has on the distribution of terrain elevation and snowpack, which in turn modulates the strength and structure of the SAF (Letcher and 
Jan.

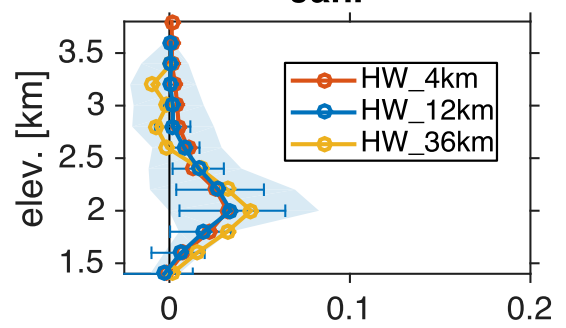

Apr.

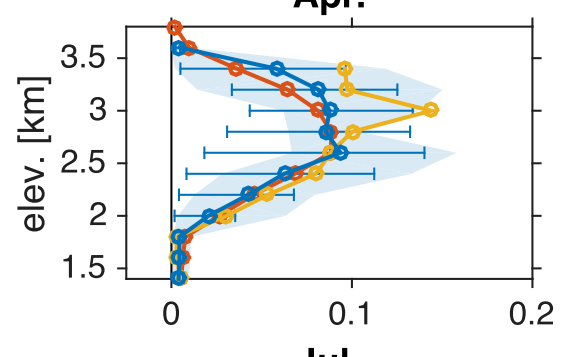

Jul.

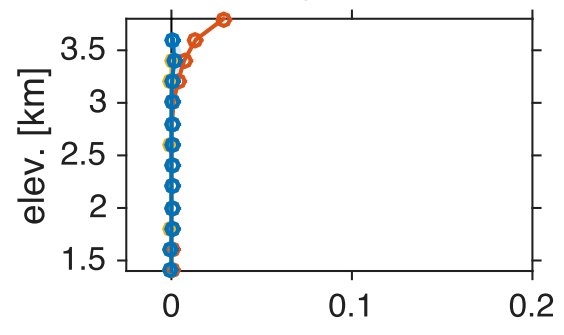

Oct.

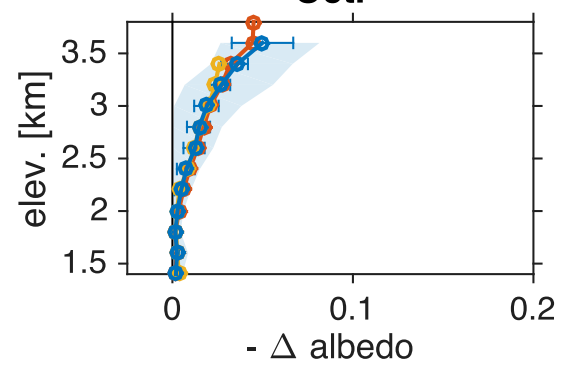

Feb.

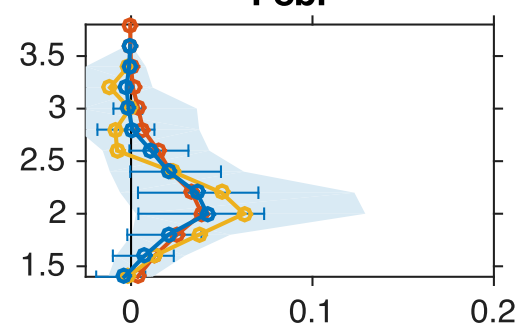

May

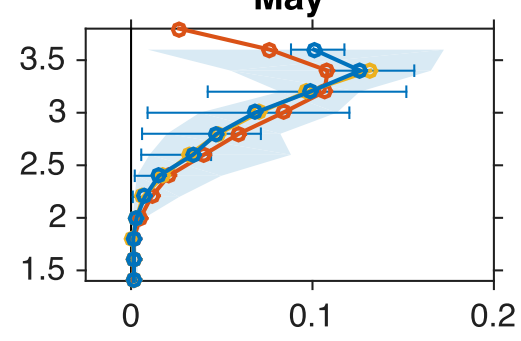

Aug.

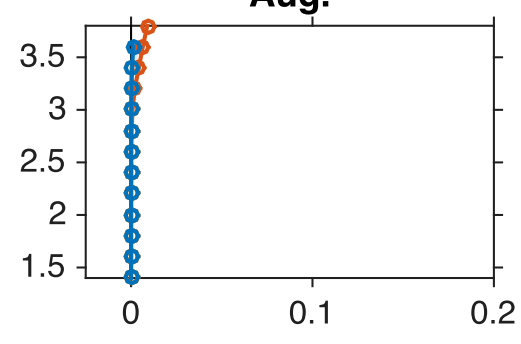

Nov.

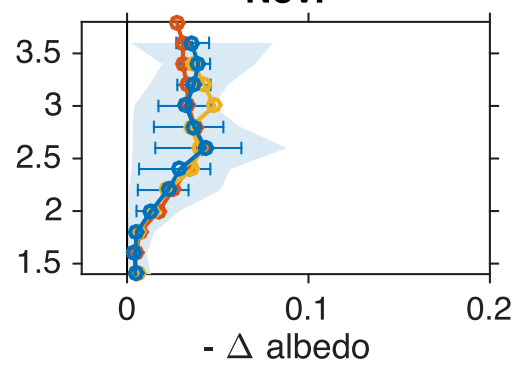

Mar.

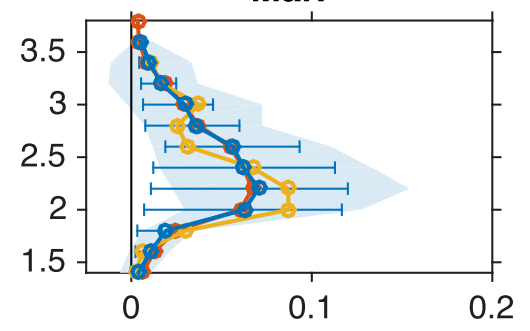

Jun.

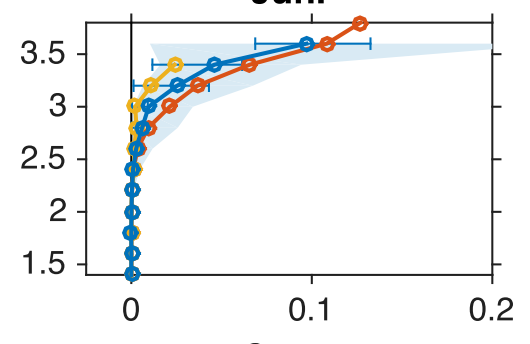

Sept.
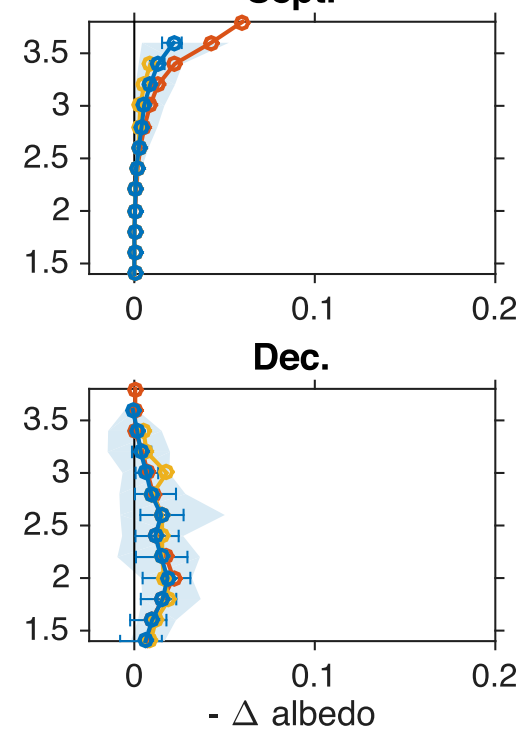

FIG. 3. As in Fig. 2 but for surface albedo. Note: the negative of the PGW - CTRL $\Delta$ albedo is plotted to enhance comparability with $\Delta T$ patterns.

Minder 2015). For instance, at $\Delta x=36 \mathrm{~km}$ high mountain peaks are not represented, limiting the accumulation of deep mountaintop snowpacks via reduced orographic precipitation and hastening snow loss due to warmer temperatures in the control climate. As a result, at this resolution there is minimal high-elevation snow present to enable a strong SAF and EDW in JuneJuly. In contrast, at $\Delta x=36 \mathrm{~km}$ the smoother terrain leads to enhanced midelevation $(2-2.5 \mathrm{~km})$ control climate snow cover relative to $\Delta x=4 \mathrm{~km}$ during JanuaryFebruary (not shown), perhaps due to a spatially broader pattern of orographic snowfall enhancement. This appears to contribute to larger midelevation albedo reductions and SAF-enhanced warming during these months.

\section{Diagnosis of mechanisms responsible for EDW}

The strong relationship between patterns of albedo reduction and warming documented in the previous section supports the hypothesis that the SAF is the dominant control on EDW over the Rockies. However, it is possible that other mechanisms also play important roles. This section presents results from the SENS experiments that better constrain the relative roles of the SAF and other mechanisms. To reduce computational 
Jan.

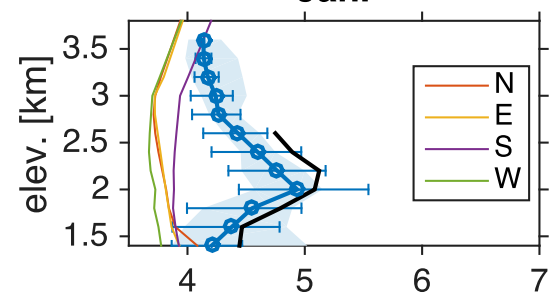

Apr.

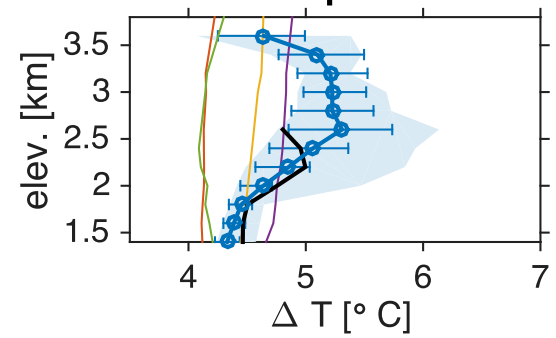

Feb.

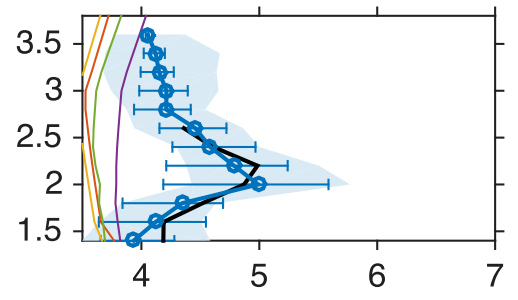

May

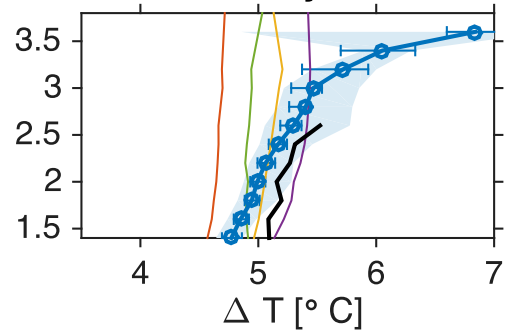

Mar.

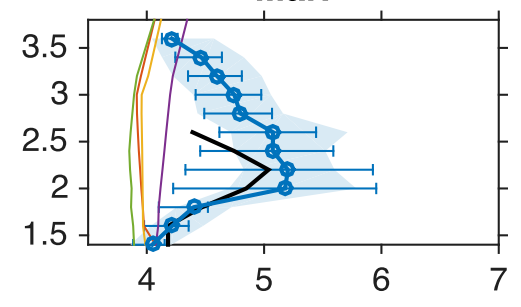

Jun.

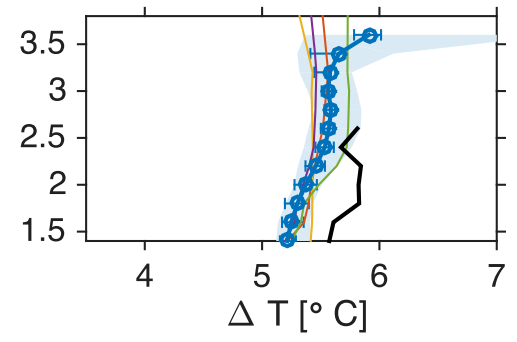

FIG. 4. Change in monthly mean 2-m temperature between SENS simulations (PGW - CTRL) $\Delta T$ binned by terrain elevation and averaged over the analysis domain. Thick blue lines show the 7-yr average $\Delta T$. Blue shading shows the interannual range of changes over the years analyzed. Horizontal whiskers show the interquartile range of the spatial variability in the multiyear average within each bin. Thin colored lines show the tropospheric warming profiles averaged along each of the lateral boundaries of the computational domain with the boundaries indicated by the legend. The thick black line shows the average change in near-surface air temperature within the analysis domain averaged across the ensemble of GCMs used to generate the PGW perturbations.

expense, the SENS experiments are all conducted with $12-\mathrm{km}$ horizontal grid spacing; however, we would expect similar results at a finer grid spacing due to the strong correspondence between simulated EDW in the 4- and 12-km HW simulations (e.g., Fig. 2). For brevity we hereafter focus on the January-June period when EDW was found to be most pronounced in the HW and SENS experiments.

Figure 4 documents the elevation dependence of warming, for January-June, in the full simulations that include a SAF (SENS-PGW - SENS-CTRL). At all elevations the warming exceeds that found in the HW simulations (Fig. 2) due to the larger PGW perturbation applied. Low-elevation warming ranges from about $4^{\circ}$ to $5^{\circ} \mathrm{C}$. EDW is found throughout these months, with some (May-June) showing a monotonic increase in $\Delta T$ with elevation while others (January-April) show midelevation maxima in $\Delta T$. Although the vertical structure of EDW is similar to the HW runs, differences in warming between elevation bins are larger, with maximum differences ranging from $0.7^{\circ} \mathrm{C}$ in June to $2.1^{\circ} \mathrm{C}$ in May.

For comparison, Fig. 4 also includes the elevation dependence of the average near-surface warming from the multi-GCM ensemble average, calculated as described in section $2 b$. Note that the plotted GCM responses do not directly constrain the WRF-simulated response because they are for the interior of the WRF computational domain while only the lateral BCs of our WRF simulations are perturbed with the PGW forcing. Results are not plotted above $2.6 \mathrm{~km}$ because the regridded terrain from the majority of the GCMs analyzed does not extend above this elevation. Despite some differences, the GCM average shows a strikingly similar pattern of EDW to that found in WRF. This may indicate that similar mechanisms are modulating EDW in WRF and the GCMs. Caution is warranted in interpretation of the GCM results since individual GCMs vary widely in their EDW, with some showing elevation dependence that is substantially stronger, weaker, or different in structure than the multi-GCM average (see Fig. S1 in the online supplemental material). The lack of grid points above about $3 \mathrm{~km}$ limits the utility of the GCMs for characterizing EDW features found in WRF, such as muted high-elevation warming in January and strongly enhanced high-elevation warming in May.

\section{a. Role of the snow albedo feedback}

The elevation dependence of albedo reductions is shown in Fig. 5. As in the HW simulations, there are substantial reductions in albedo associated with the loss of snow cover. The albedo reductions maximize at midelevations, around $2.2 \mathrm{~km}$, in January. This maximum progresses upward in elevation throughout the spring and is located in the highest elevations during May and June. As in the HW simulations, these patterns 
Jan.

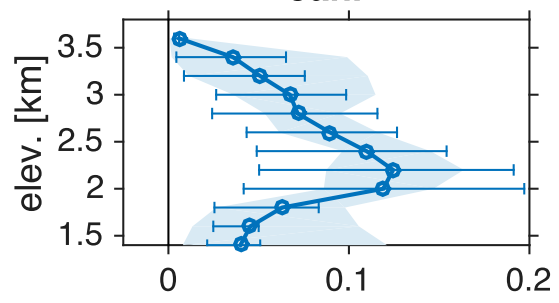

Apr.

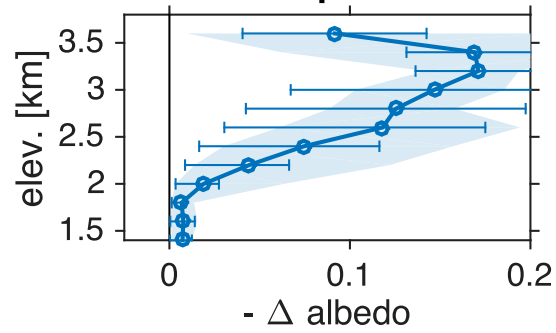

Feb.

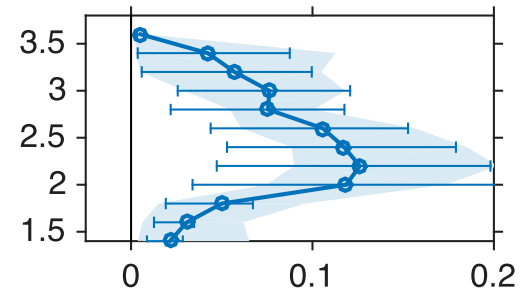

May

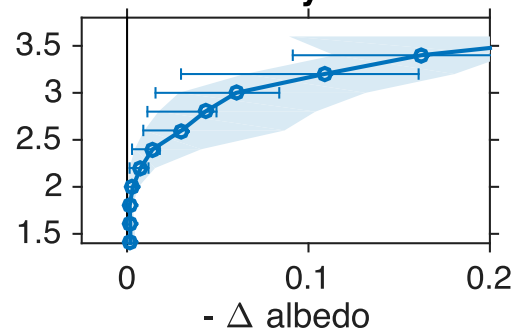

Mar.

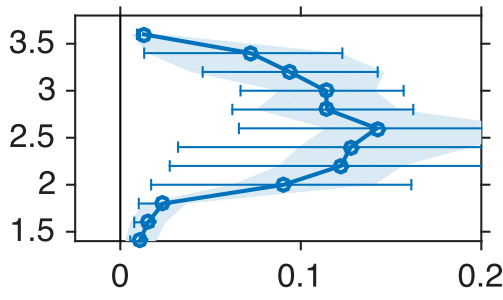

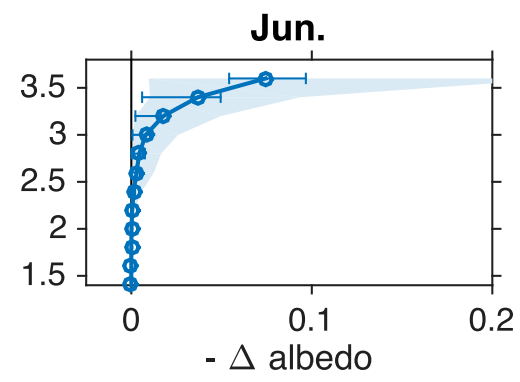

FIG. 5. As in Fig. 4, but for surface albedo changes. Note: the negative of the PGW - CTRL $\Delta$ albedo is plotted to enhance comparability with $\Delta T$ patterns.

of albedo reduction generally mirror the patterns of warming (Fig. 4).

The spatial correlation between warming and albedo reductions is also apparent when mapping the changes, as shown in Fig. 6 for the months of March $\left(r^{2}=0.78\right)$ and May $\left(r^{2}=0.66\right)$. There are some notable differences in the structures of warming and albedo reduction shown in Figs. 4-6, such as the broader spatial extent of enhanced warming relative to albedo reductions. However, these differences may be consistent with our understanding of the SAF, since patterns of SAF-enhanced warming are modulated by variations in solar radiation and shaped by atmospheric transport of SAF-enhanced warming away from regions of snow loss (Letcher and Minder 2015).

We more directly quantify the enhancement of warming by the SAF $\Delta_{\mathrm{SAF}} T$ by comparing $2-\mathrm{m}$ temperatures between perturbed climate simulations with variable and fixed albedos (SENS-PGW - SENS-FA). The elevation dependence of this difference is shown in Fig. 7. These results indicate that the SAF enhances warming by up to $1.5^{\circ} \mathrm{C}$, and the elevation-dependent structure of this enhancement closely follows the EDW found in the full climate change experiment (Fig. 4). During February-May there are elevation bands where $\Delta_{\mathrm{SAF}} T$ accounts for over $20 \%$ of the total $\Delta T$. Examples of the spatial structure of $\Delta_{\mathrm{SAF}} T$ are shown for March and May in Fig. 8. These reveal that enhancement of warming by the SAF is spatially extensive and exceeds $3.5^{\circ} \mathrm{C}$ at some locations. Comparison with Fig. 6 shows that the spatial structure of $\Delta_{\mathrm{SAF}} T$ correlates well with the $\Delta T$ from the full climate change experiment (March: $r^{2}=0.92$, May: $r^{2}=0.43$ ).
We also quantify the structure of climate warming in the absence of the SAF $\Delta_{\text {noSAF }} T$ by comparing the control and fixed albedo simulations (SENS-FA SENS-CTRL). Without the SAF the EDW is mostly eliminated, as is much of the spatial variability of warming within elevation bands (Fig. 9). Interannual variability in the warming is also greatly reduced, since year-to-year variations in snow cover lead to variations in the structure of SAF-enhanced warming (Letcher and Minder 2015). Example maps of $\Delta_{\mathrm{noSAF}} T$ from March and May (Fig. 8) depict a much more uniform pattern of warming than in the full PGW response. Without an active SAF there still appears to be some tendency for enhanced warming in regions of snow loss. This may reflect non-albedo-related effects of snow cover reduction, such as changes in the surface energy budget associated with reduced energy inputs into snowpack melting.

\section{b. Role of the free-tropospheric EDW}

To investigate the possible role of GCM-predicted large-scale free-tropospheric EDW in shaping the simulated surface EDW we also plot the GCM ensemble-mean atmospheric $\Delta T$ perturbations used to force the model. These are represented by differencing the WRF atmospheric temperatures along each of the four lateral BCs between the climate states (PGW - CTRL), interpolating to a common regular vertical grid (from WRF's native terrain-following coordinate), and then averaging along each lateral boundary. Note that this GCM-predicted free-tropospheric EDW may differ somewhat from reality if GCM 
$\Delta \mathrm{T}$
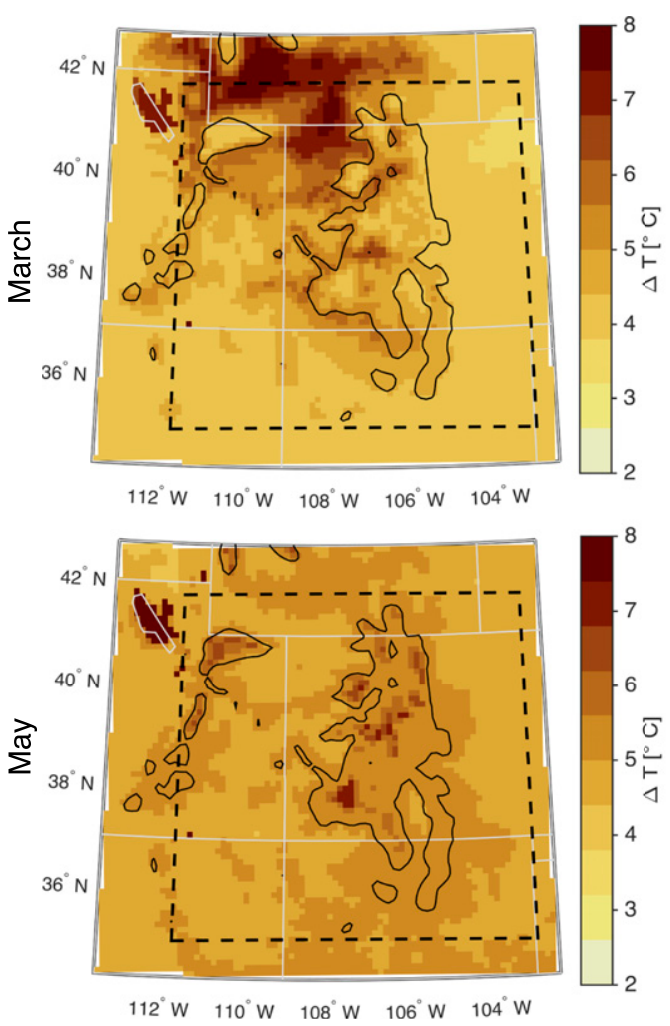

$\Delta$ albedo
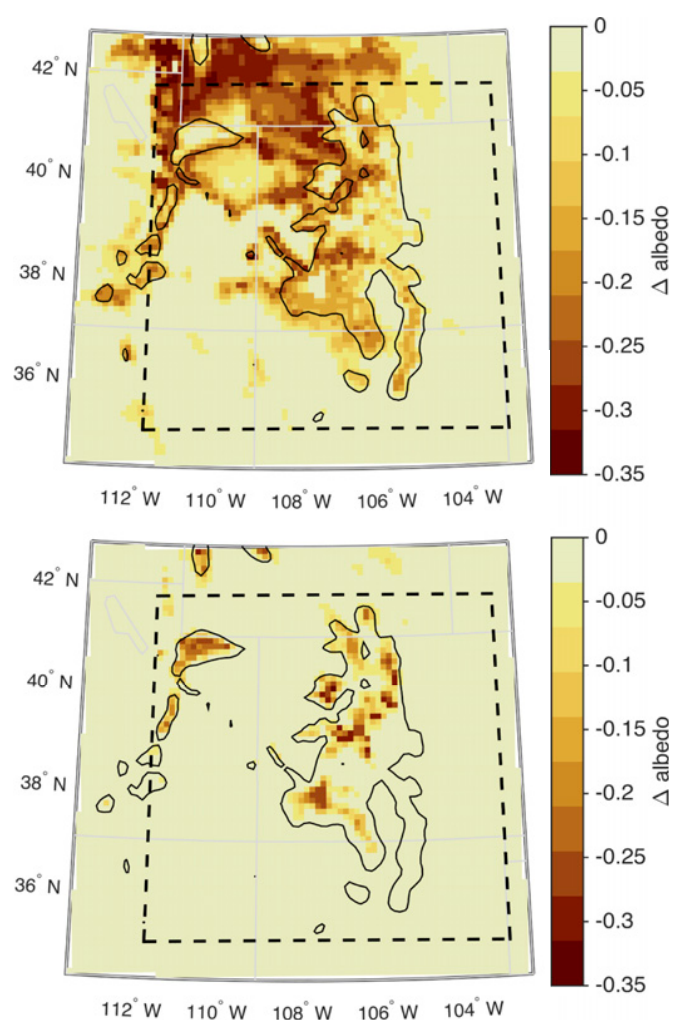

FIG. 6. Monthly mean changes (PGW - CTRL) in (left) 2-m temperature and (right) albedo for the SENS experiments averaged over 7-yr analysis period. Results are shown for two select months: (top) March and (bottom) May. The $2.5-\mathrm{km}$ terrain elevation is contoured. State boundaries are shown with thin gray lines.

temperature profiles are biased due to poor terrain resolution. Also, note that we do not diagnose the causes of the GCM-predicted free-tropospheric EDW, which may be affected by processes such as the SAF and WVFs in the GCM.

Results are plotted as thin colored lines in Figs. 4 and 9. These profiles reveal that there is minimal EDW in the tropospheric PGW perturbation applied at the lateral BCs. While some BC warming profiles show a modest increase in $\Delta T$ with elevation, maximum differences between elevation bins are only about $0.2^{\circ}-$ $0.4^{\circ} \mathrm{C}$. In January-May, RCM-simulated surface $\Delta T$ exceeds the $\mathrm{BC}$ tropospheric $\Delta T$ by upward of $1^{\circ} \mathrm{C}$ in the elevation bands where surface warming is maximized. Only in June does surface $\Delta T$ appear to track the BC tropospheric changes. When comparing to the $\mathrm{BC}$ tropospheric changes to the $\Delta_{\text {noSAF }} T$ response, a stronger correspondence is found, particularly in JanuaryFebruary and May (Fig. 9). These results suggest that while large-scale tropospheric EDW may contribute somewhat to the simulated surface EDW, the role of this mechanism is secondary to that of the SAF during the January-May period.

\section{c. Role of elevation-dependent water vapor feedback}

To examine the possible influence of an elevationdependent WVF on EDW, we plot the elevation dependence of changes (PGW - CTRL) in surface downwelling longwave radiation $\triangle$ DLR (Fig. 10). Previous studies have presented statistical relationships between warming and increases in DLR to argue for the role of the WVF as a contributor to EDW (e.g., Rangwala et al. 2010, 2016; Palazzi et al. 2017). If the WVF were a primary contributor to simulated EDW then we would expect to find positively correlated elevation-dependent variations in $\triangle D L R$ and $\Delta T$ (or $\left.\Delta_{\mathrm{noSAF}} T\right)$. Instead, our results show variations in $\triangle \mathrm{DLR}$ that do not exhibit a strong relationship with variations in $\Delta T$. For example, during May-June $\Delta$ DLR generally decreases with elevation while $\Delta T$ increases with elevation. Based on these results we conclude that changes in DLR associated with the WVF are unlikely to contribute significantly to EDW in our simulations.

Overall, the results of this section support the hypothesis that the SAF is the dominant mechanism shaping EDW in these simulations. Large-scale free-tropospheric 
Jan.

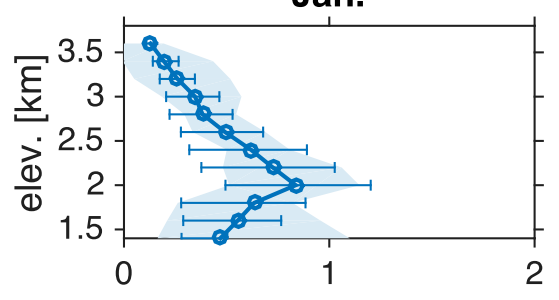

Apr.

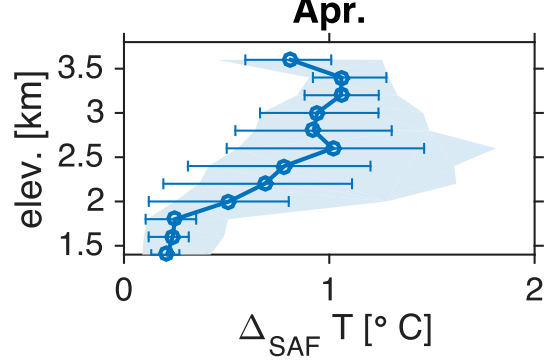

Feb.

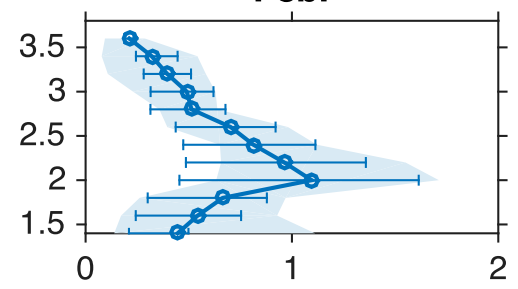

May

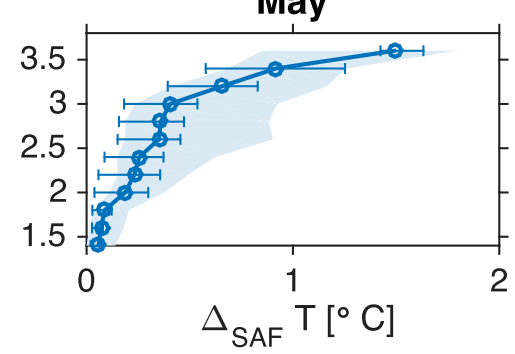

Mar.

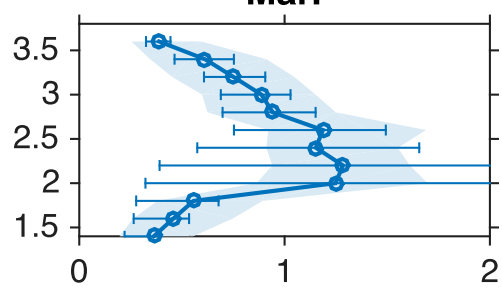

Jun.

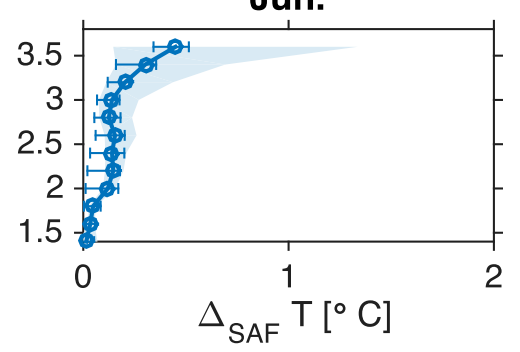

FIG. 7. As in Fig. 4, but for changes between the PGW and FA experiments (PGW - FA) in order to quantify the contribution of the SAF to warming $\Delta_{\mathrm{SAF}} T$.

EDW appears to also play a role, albeit a much smaller one. While other mechanisms may contribute to EDW, such as an elevation-dependent WVF, these do not appear to be strong or systematic enough to notably affect the overall surface warming profile in these simulations.

\section{Sensitivity of snow cover, surface albedo, and EDW to land surface model}

Motivated by the above-described importance of the SAF in shaping EDW, we now characterize the sensitivity of EDW to the choice of LSM by comparing the above SENS simulations, which use the Noah LSM, with additional simulations that use Noah-MP (SENS-NMP). As discussed in Minder et al. (2016), the differences in how these two LSMs parameterize snow physics and treat snow-canopy-radiation interactions may affect the strength and character of the simulated SAF.

\section{a. Evaluation against satellite-estimated snow cover}

Before comparing EDW between simulations with differing LSMs, we first evaluate the skill of the CTRL simulations in reproducing satellite-estimated snow cover from the MODIS MODSCAG product as described in section 2c. The average seasonal cycle of $f_{\mathrm{SCA}}$, SWE, and albedo over our analysis domain are plotted in Fig. 11. The domain-averaged snow extent (Fig. 11a) is calculated as the percentage of the analysis domain with "snowy" pixels that have $f_{\mathrm{SCA}}>0.15$, the detection threshold for MODSCAG. The SENS results closely track the MODSCAG-estimated snow extent, whereas
SENS-NMP shows a persistent negative bias. When averaging $f_{\text {SCA }}$ over snowy pixels only (Fig. 11b), SENS is found to have a positive bias that increases with time over the course of the snow season, whereas SENSNMP has a negative bias that is reduced with time. The net effect of the biases in snow extent and snowy-pixel $f_{\mathrm{SCA}}$ is that the domain-averaged $f_{\mathrm{SCA}}$ (Fig. 11c) is biased modestly high in SENS and substantially low in SENSNMP. Despite the large differences in snow cover, the domain-averaged SWE is quite similar in the two simulations (Fig. 11d), suggesting that the disparities are predominately caused by differences in how $f_{\mathrm{SCA}}$ is parameterized as a function of SWE. The large differences in $f_{\mathrm{SCA}}$ between the two simulations translate to large differences in surface albedo (Fig. 11e) that reach as high as 0.15 .

These results are consistent with those of Minder et al. (2016), who compared two high-resolution RCM simulations to MODSCAG over a similar domain. They considered the same HW simulations analyzed in this study as well as the CONUS simulations described by Liu et al. (2017), both with a horizontal grid spacing of $4 \mathrm{~km}$. The simulations they considered also utilized the same contrasting LSMs: Noah (HW) and NoahMP (CONUS). However, the HW and CONUS simulations also differed in several other aspects of their configuration, so differences in their performance could not be unambiguously attributed to LSM choice. Our results closely mirror those of Minder et al. (2016; their Fig. 8), with very similar differences found between simulations using Noah and Noah-MP and similar biases relative to MODSCAG. This supports their hypothesis 

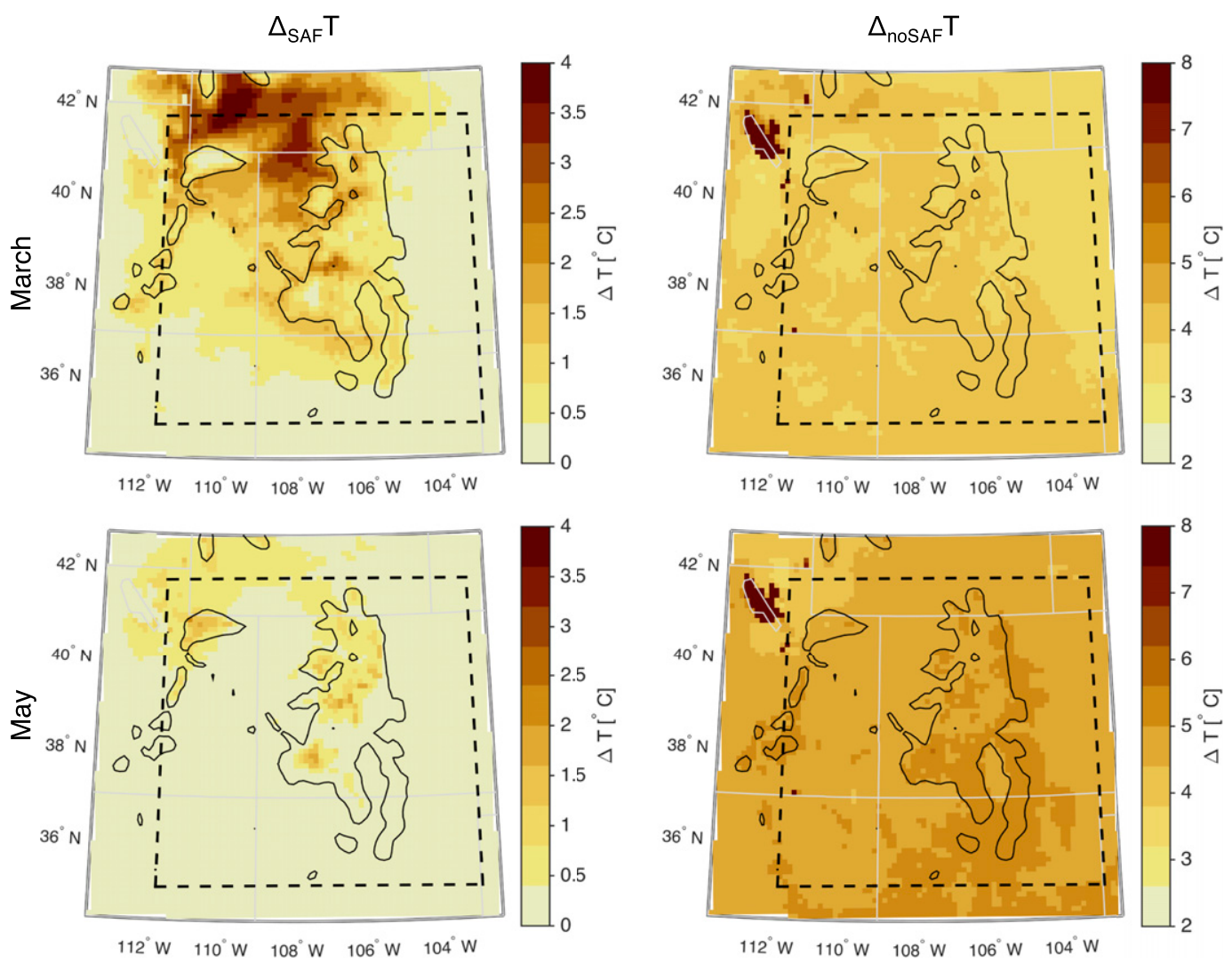

FIG. 8. Results from the SENS-FA simulation. Monthly mean changes averaged over the 7-yr analysis period are plotted for (top) March and (bottom) May. Shown are (left) the change in 2-m temperature associated with the SAF $\Delta_{\mathrm{SAF}} T$ calculated as the difference between the SENS-PGW and SENS-FA experiments, and (right) the change in in 2-m temperature in the absence of the SAF $\Delta_{\mathrm{noSAF}} T$ calculated as the difference between the SENS-FA and SENS-CTRL experiments. The $2.5-\mathrm{km}$ terrain elevation is contoured. State boundaries are shown with thin gray lines.

that the differences they documented were primarily attributable to differing treatments of snow processes in Noah versus Noah-MP.

\section{b. Difference in EDW between land surface models}

Figure 12 shows that the SENS-NMP simulations also produce EDW throughout the January-June period, but the magnitude, variability, and elevation dependence of the warming are reduced relative to SENS. Maps of $\Delta T$ also show a more uniform warming (e.g., Fig. 13). The largest differences are found in the midelevation warming maximum during February-April, when certain elevation bands experience reductions in warming of $1^{\circ} \mathrm{C}$ or more when using Noah-MP instead of Noah. This reduced warming is nearly ubiquitous; for example, in March $\Delta T$ is almost everywhere smaller in SENSNMP as compared to SENS, and local differences exceed $2^{\circ} \mathrm{C}$ over a large region (Fig. S2).

These differences in warming appear to be explained by differences in the SAF. Albedo reductions are substantially smaller, and generally less variable, in the Noah-MP experiment (Figs. 13 and 14; see also Fig. S2), limiting the amplification of warming by the SAF and its variability. These differences in the albedo response are particularly pronounced in middle elevations $(2-3 \mathrm{~km})$ during March-April, with spatial structures that largely match the differences in warming (e.g., Fig. S2). Despite different albedo responses, warming profiles are more similar in May and June, perhaps because large-scale free-tropospheric warming plays a larger role in EDW during these months (e.g., Fig. 9).

The very different albedo response, SAF, and EDW between simulations with Noah and Noah-MP are caused by a strong sensitivity of control climate snow cover and surface albedo to the choice of LSM. Figure 15 compares the profiles of surface albedo between the CTRL simulations of the two experiments. Albedo in the SENS simulation is consistently larger than in the SENS-NMP simulation, by as much as 0.31 , especially at midelevations around $2.5 \mathrm{~km}$. Maps of albedo also reveal 
Jan.

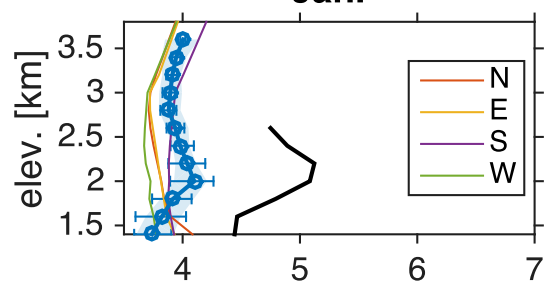

Apr.

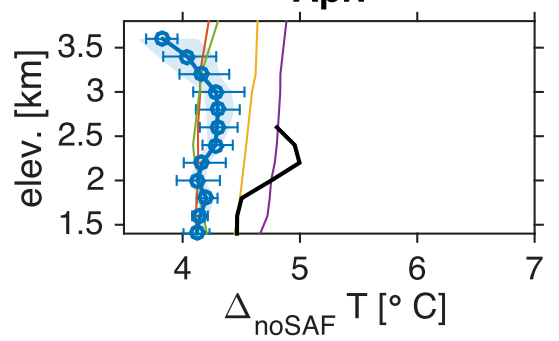

Feb.

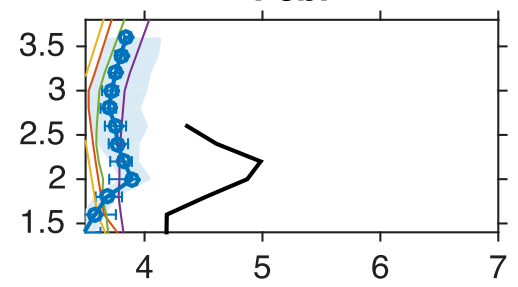

May

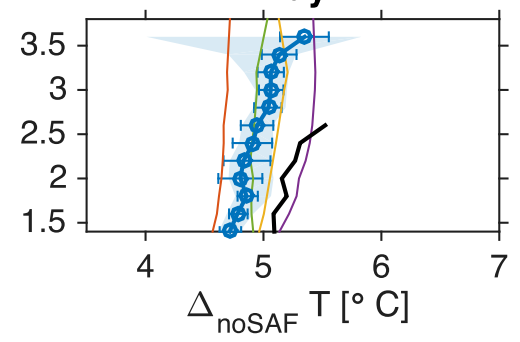

Mar.

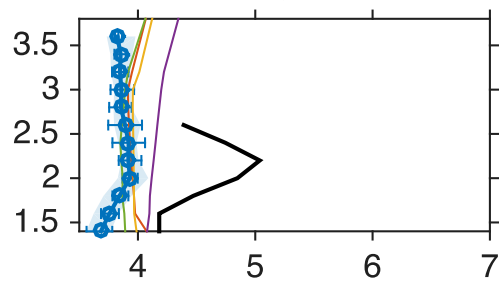

Jun.

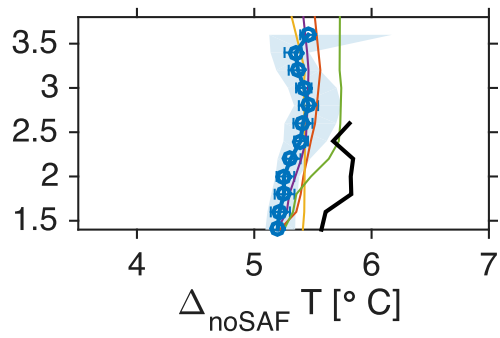

FIG. 9. As in Fig. 4, but for changes between the FA and CTRL experiments (FA - CTRL) in order to quantify the warming response in the absence of a SAF $\Delta_{\text {noSAF }} T$. Note that the tropospheric boundary warming profiles (thin colored lines) and GCM surface warming profiles (thick black lines) are the same as in Fig. 4.

consistently larger surface albedo in SENS throughout the analysis region (e.g., Fig. S3).

One cause of these differences in surface albedo is reduced SWE in SENS-NMP relative to SENS in the 2-2.6-km elevation range during January-March (Fig. 16). This is apparent in maps of SWE and albedo as a large region of absent snow and low albedo in SENS-NMP near the intersection of the Utah, Wyoming, and Colorado borders (e.g., Fig. S3).
However, differences in SWE do not fully account for the difference in albedo between the two LSMs. At elevations above about $2.6 \mathrm{~km}$ the SENS-NMP simulations produce more SWE but lower surface albedo relative to SENS (Figs. 15 and 16; see also Fig. S3). Over these regions, differences in albedo are dominated by differences in how subpixel snow cover and surface albedo are parameterized as a function of SWE and vegetation type in Noah versus Noah-MP. These sensitivities are likely
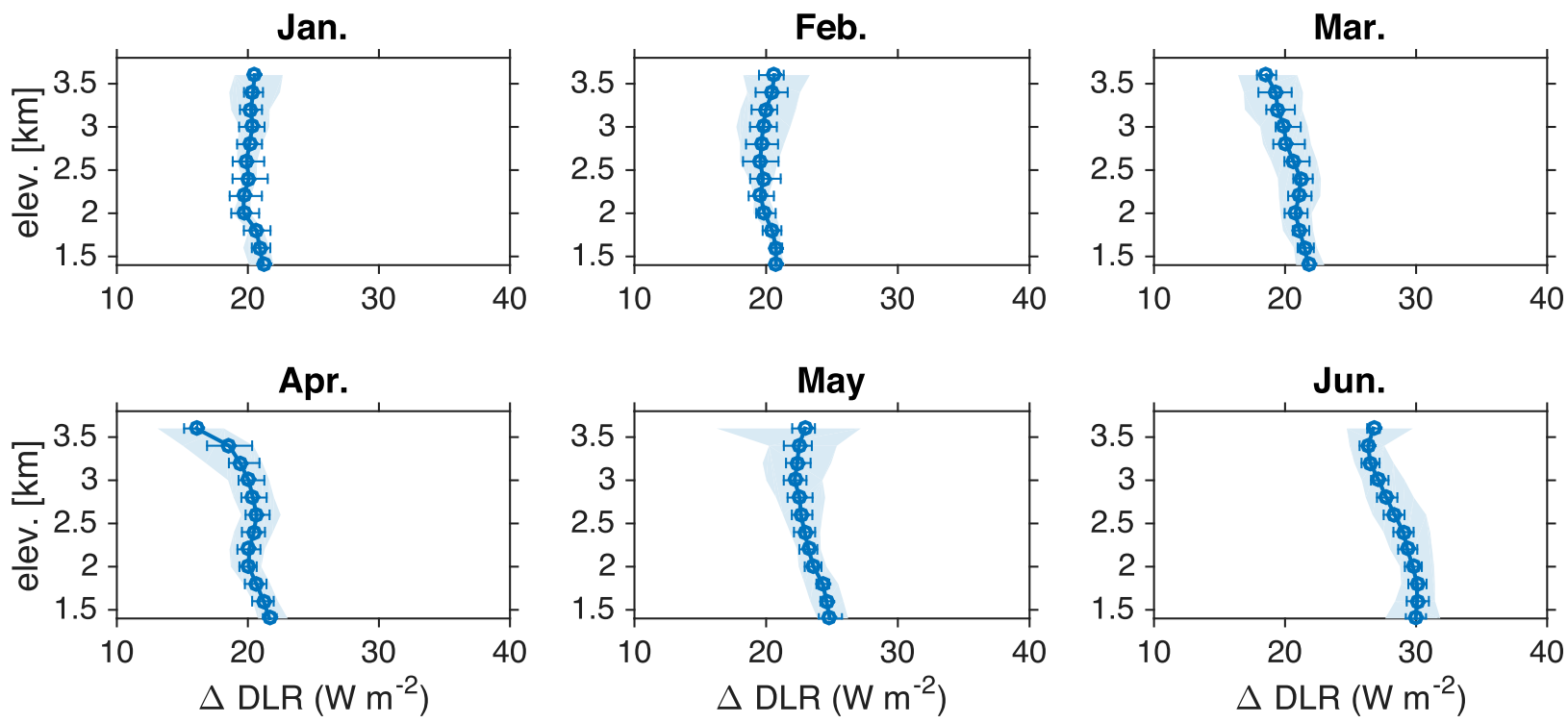

FIG. 10. As in Fig. 4, but for surface DLR changes. 

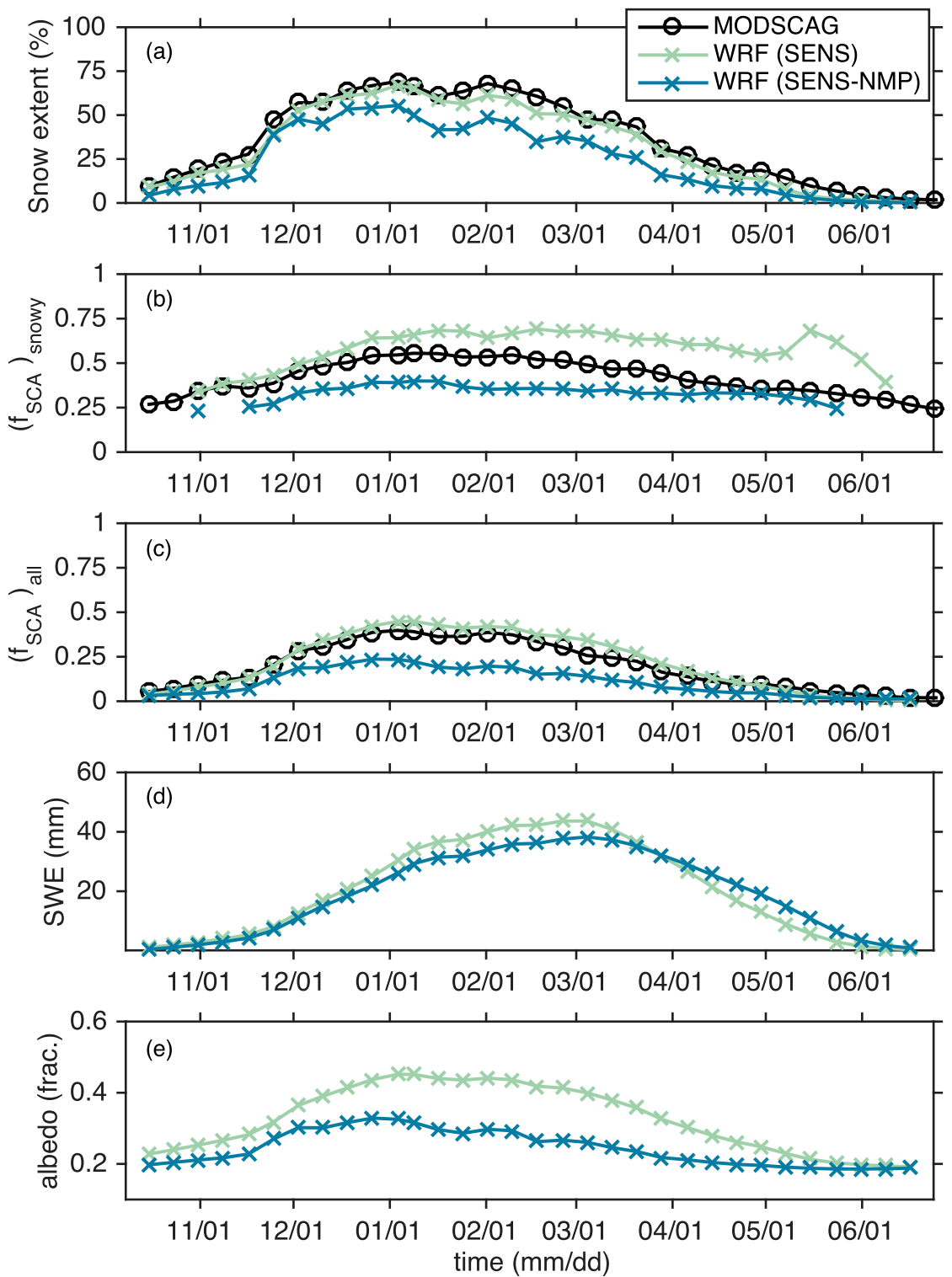

FIG. 11. Seasonal cycle of surface snow and albedo variables averaged over the analysis domain (denoted in Fig. 1) and averaged over the 7-yr analysis period for the CTRL simulations of the SENS (Noah) and SENS-NMP (Noah-MP) experiments. Data plotted are 16day average values. Black lines are satellite-based estimates from the MODSCAG product. Individual panels show the following: (a) snow extent, defined as the fraction of the domain with "snowy pixels" corresponding to $f_{\mathrm{SCA}}>0.15$, (b) $f_{\mathrm{SCA}}$ averaged over snowy pixels, (c) $f_{\mathrm{SCA}}$ averaged over all pixels, (d) SWE, and (e) surface albedo.

enhanced by the presence of extensive forest cover in the 2.5-3.5-km elevation range (Figs. 1d,e), which increases the importance of accurately representing canopy-snowradiation interactions.

These strong sensitivities suggest that evaluating and improving the representation of surface snow cover and its effect on albedo is essential for constraining simulations of EDW. The biases in simulated $f_{\mathrm{SCA}}$ documented above for the CTRL simulations suggest that there are likely corresponding biases in their simulated SAF and, consequently, EDW. Specifically, the Noah-based SENS simulation likely overpredicts SAF-enhanced warming and EDW due to artificially high $f_{\mathrm{SCA}}$ and albedo over snowy pixels, which leads to excessive albedo reductions when snow cover is reduced in a warmed climate. On the other hand, the Noah-MP-based SENS-NMP simulation likely underpredicts SAF-enhanced warming near the low-elevation margin of the observed snowpack due to 
Jan.

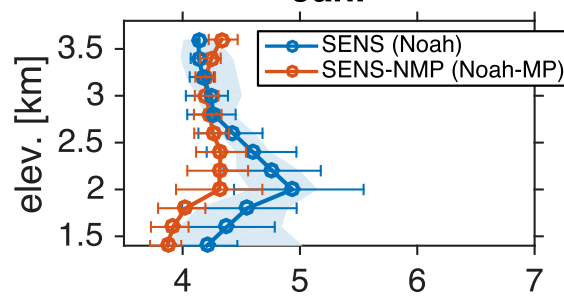

Apr.

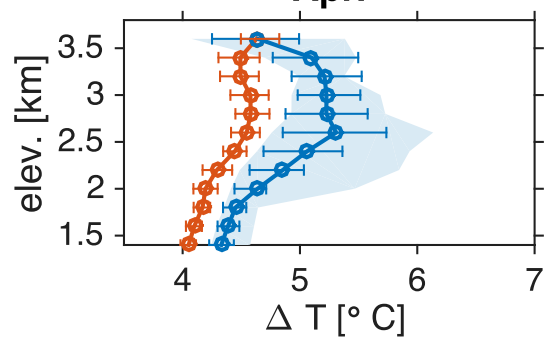

Feb.

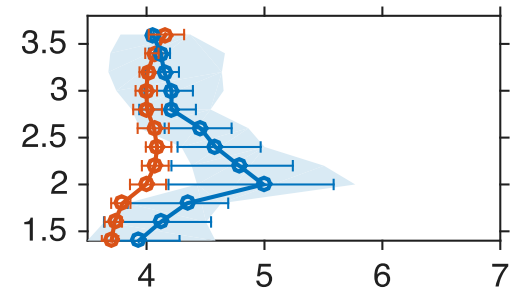

May

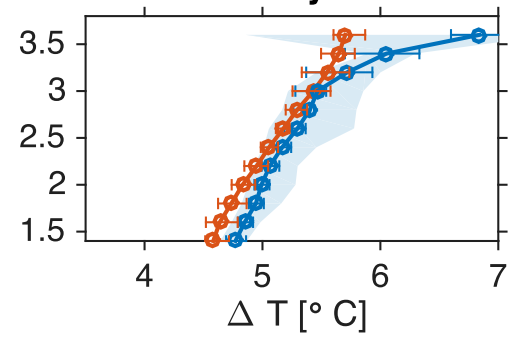

Mar.

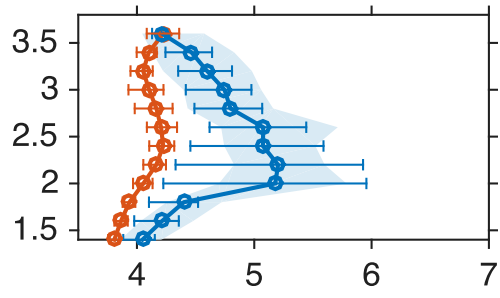

Jun.

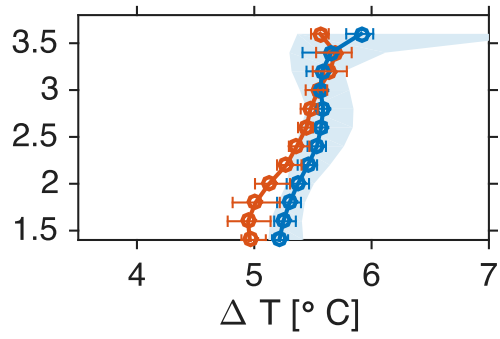

FIG. 12. As in Fig. 4, but comparing results between simulations with different LSMs: SENS (using Noah) and SENS-NMP (using NoahMP).

insufficient extent of low-elevation snow cover, leading to an upslope displacement of SAF-enhanced warming that will bias estimates of EDW structures.

\section{Summary and conclusions}

This study analyzed the character and causes of elevation-dependent warming (EDW) of surface temperatures in a suite of regional climate model (RCM) simulations of climate change over the Rocky Mountains. We summarize our primary findings and conclusions below.

- A clear EDW signal is found over the region, but its structure varies strongly with season. During some months warming maximizes at middle elevations, whereas during others it increases monotonically with elevation, or is nearly independent of elevation. Warming is enhanced in certain elevation bands by as much as $2^{\circ} \mathrm{C}$.

- In these simulations EDW is primarily caused by the elevation dependence of the snow albedo feedback (SAF). Warming maximizes in elevation ranges of maximum snow loss and albedo reduction, which vary with season following the margin of the seasonal snowpack. This is consistent with the important role of the SAF suggested by many previous RCM studies of EDW (e.g., Im et al. 2010; Kotlarski et al. 2015; Winter et al. 2017; Rupp et al. 2017; Walton et al. 2017). The role of the SAF is confirmed by sensitivity experiments wherein the SAF is artificially suppressed. These demonstrate that the SAF enhances warming in certain elevation bands by as much as $1.5^{\circ} \mathrm{C}$ and that without an active SAF most EDW is eliminated.

- In these simulations the elevation dependence of large-scale GCM-predicted free-tropospheric warming appears to play only a secondary, and relatively minor, role in shaping EDW. We find no evidence for the role of an elevation-dependent water vapor feedback in contributing to EDW. Our results do not speak to the potential role of other factors, such as elevationdependent changes in vegetation or aerosol loading, that may also affect EDW since these factors are held fixed in our simulations.

- The structure and magnitude of simulated EDW is sensitive to grid resolution. Simulations using 4- and 12-km horizontal grid spacings show similar EDW signals, but substantial differences are found for simulations with a grid spacing of $36 \mathrm{~km}$ due to the influence of terrain resolution on the evolution of snow cover and the SAF. Consequently, some moderate-resolution RCMs (with grid spacings of tens of kilometers) may have substantial biases in their simulated pattern of EDW over complex terrain. The average climate change response of multiple GCMs exhibits similar EDW as our RCM simulations, despite the coarser resolutions of the GCMs. However, individual GCM responses vary widely, and GCMs do not provide information on high-elevation warming.

- The structure and magnitude of simulated EDW is sensitive to land surface model choice. A pair of 

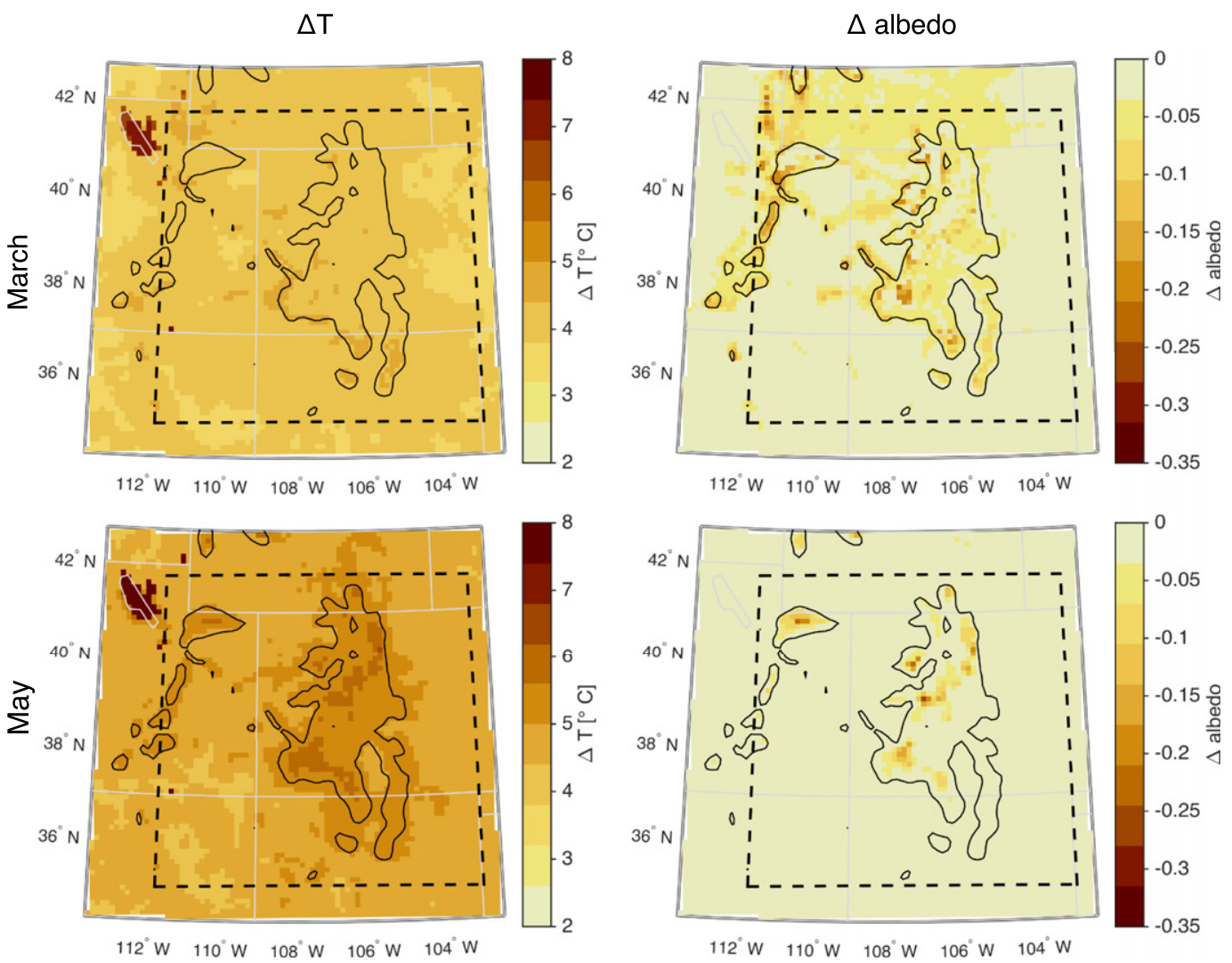

FIG. 13. As in Fig. 6, but for SENS-NMP simulations using the Noah-MP LSM.

simulations using the Noah and Noah-MP land surface models (LSMs) both show pronounced EDW but with different magnitudes and structures. The differences between LSMs are caused by their differing control climate patterns of surface albedo associated with differences in their simulated extent of midelevation snow cover and their parameterization of subpixel fractional snow cover. These albedo differences act to
Jan.

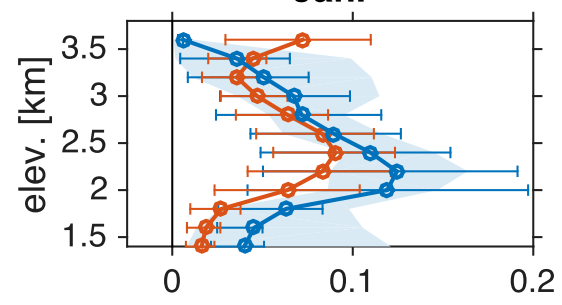

Apr.

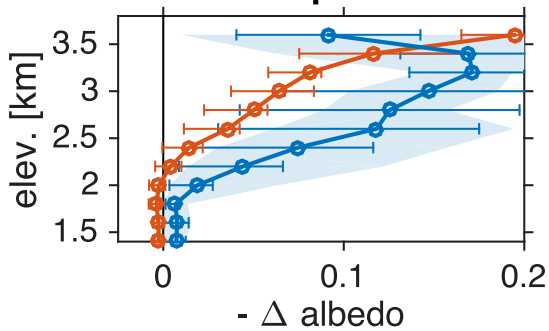

Feb.

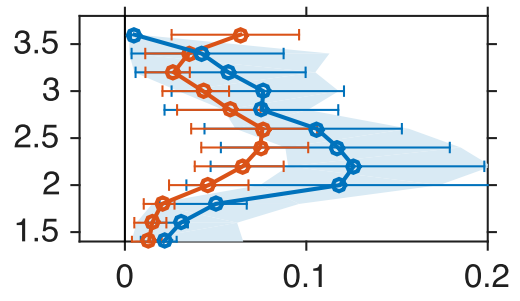

May

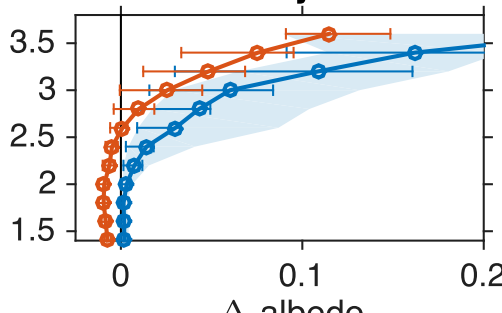

Mar.

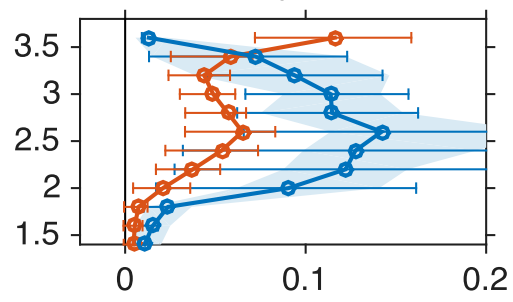

Jun.

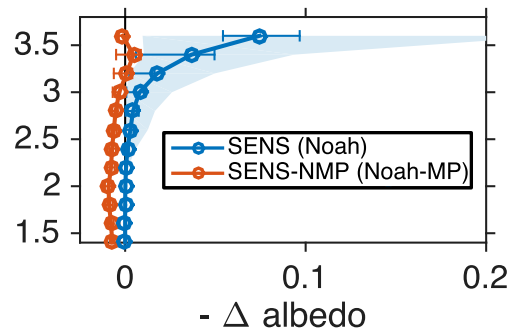

FIG. 14. As in Fig. 5, but comparing results between simulations with the Noah LSM (SENS) and Noah-MP LSM (SENS-NMP). The negative of PGW - CTRL $\Delta$ albedo is plotted to enhance comparability with DT patterns. 
Jan.

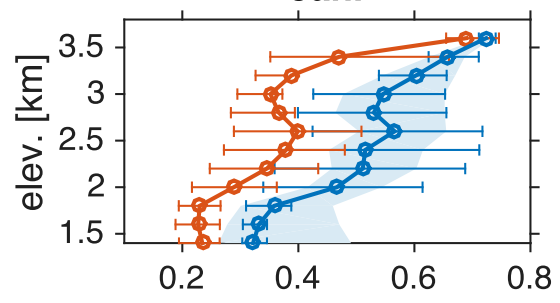

Apr.

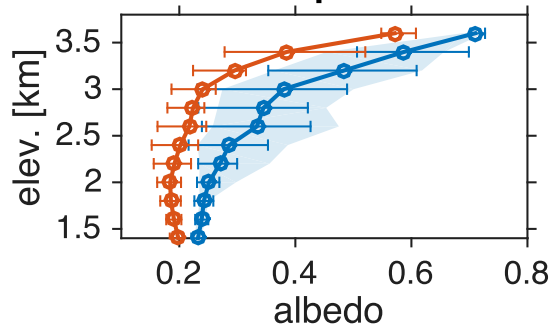

Feb.

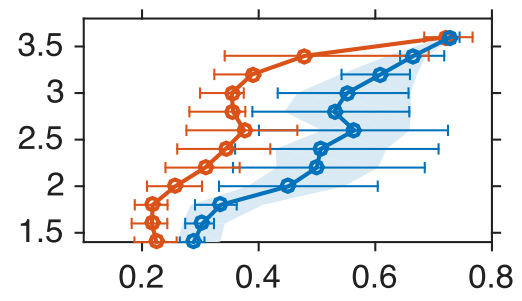

May

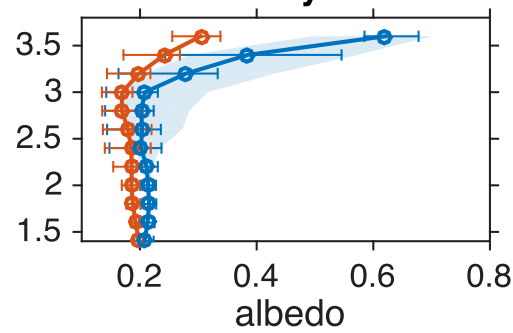

Mar.

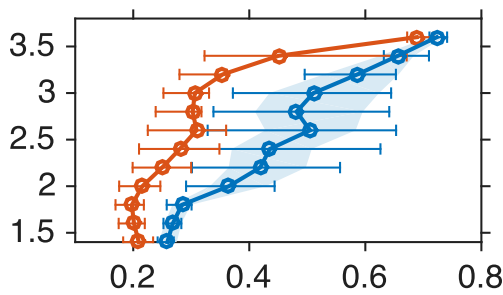

Jun.

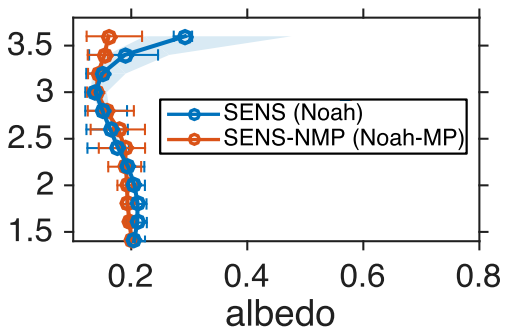

FIG. 15. As in Fig. 12, but for albedo from the CTRL climate.

modulate the simulated SAF and its effect on EDW. Both simulations exhibit biases in their simulated snow cover relative to satellite estimations, which suggest that both have important biases in their simulated SAF and EDW. Because of the large sensitivity of simulated warming to LSM parameterization of snow processes, improvements to these aspects of LSMs, via added physical realism or observational constraints, would likely improve simulations of warming patterns over mountains with significant seasonal snow cover.
These results apply specifically to our study area, the Rocky Mountains, and the climate change scenarios considered. The relative importance of various mechanisms to EDW may vary with setting. For instance the SAF would likely play a reduced role in regions with more persistent cloud cover and the role of freetropospheric warming may be enhanced in RCMs forced by GCMs that have larger changes in tropospheric lapse rates. Further work should utilize high-resolution RCM simulations to test the generality of these results by

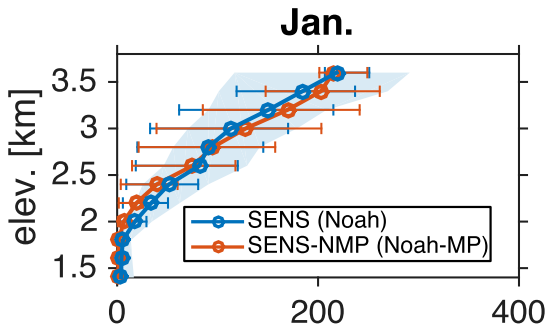

Feb.

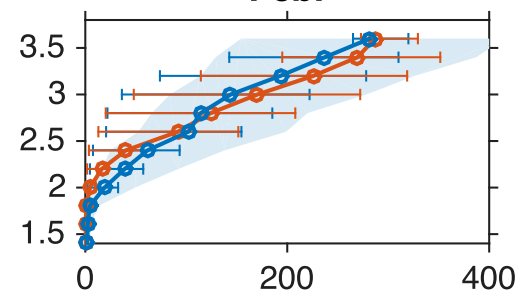

May

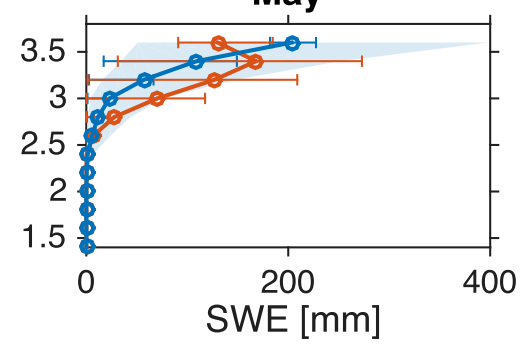

Mar.

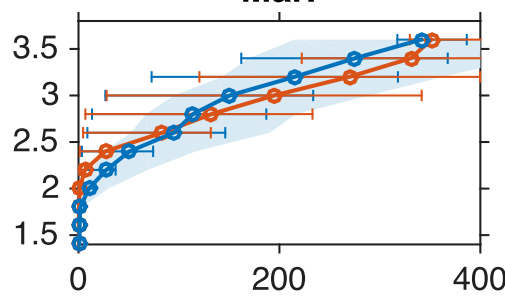

Jun.

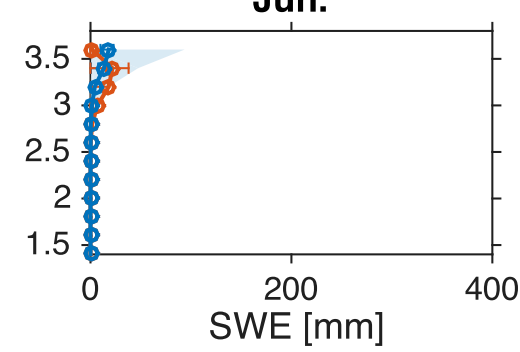

FIG. 16. As in Fig. 15, but for SWE from the CTRL climate. 
examining the character and causes of EDW across different mountain ranges and climate scenarios.

Acknowledgments. This work was supported by NSF Grant AGS-1349990. The NCAR Water System program, funded by the NSF, supported the generation of the HW simulations. High-performance computing support was provided by NCAR's Computational and Information Systems Laboratory, sponsored by the NSF. Output from all simulations presented is archived at NCAR and available upon request. We acknowledge the constructive comments of three anonymous reviewers, which helped to improve the manuscript.

\section{REFERENCES}

Barlage, M., and Coauthors, 2010: Noah land surface model modifications to improve snowpack prediction in the Colorado Rocky Mountains. J. Geophys. Res., 115, D22101, https:// doi.org/10.1029/2009JD013470.

Beniston, M., 2003: Climatic change in mountain regions: A review of possible impacts. Climatic Change, 59, 5-31, https://doi.org/ 10.1023/A:1024458411589.

Bradley, R. S., F. T. Keimig, and H. F. Diaz, 2004: Projected temperature changes along the American cordillera and the planned GCOS network. Geophys. Res. Lett., 31, L16210, https://doi.org/10.1029/2004GL020229.

Chen, Fei, and J. Dudhia, 2001: Coupling an advanced land surface-hydrology model with the Penn State-NCAR MM5 modeling system. Part I: Model implementation and sensitivity. Mon. Wea. Rev., 129, 569-585, https://doi.org/10.1175/ 1520-0493(2001)129<0569:CAALSH > 2.0.CO;2.

_ in the complex terrain and forested Colorado Headwaters region: A model intercomparison study. J. Geophys. Res. Atmos., 119, 13 795-13 819, https://doi.org/10.1002/2014JD022167.

Chen, Feng, C. Liu, J. Dudhia, and M. Chen, 2014: A sensitivity study of high-resolution regional climate simulations to three land surface models over the western United States. J. Geophys. Res. Atmos., 119, 7271-7291, https://doi.org/ 10.1002/2014JD021827.

Collins, W. D., and Coauthors, 2006: The Community Climate System Model version 3 (CCSM3). J. Climate, 19, 2122-2143, https://doi.org/10.1175/JCLI3761.1.

Daly, C., M. Halbleib, J. I. Smith, W. P. Gibson, M. K. Doggett, G. H. Taylor, J. Curtis, and P. P. Pasteris, 2008: Physiographically sensitive mapping of climatological temperature and precipitation across the conterminous United States. Int. J. Climatol., 28, 2031-2064, https://doi.org/10.1002/joc.1688.

Diaz, H. F., and J. K. Eischeid, 2007: Disappearing "alpine tundra" Köppen climatic type in the western United States. Geophys. Res. Lett., 34, L18707, https://doi.org/10.1029/2007GL031253.

Ek, M. B., K. E. Mitchell, Y. Lin, E. Rogers, P. Grunmann, V. Koren, G. Gayno, and J. D. Tarpley, 2003: Implementation of Noah land surface model advances in the National Centers for Environmental Prediction operational mesoscale eta model. J. Geophys. Res., 108, 8851, https://doi.org/10.1029/ 2002JD003296.

Fyfe, J. C., and G. M. Flato, 1999: Enhanced climate change and its detection over the Rocky Mountains. J. Climate, 12, 230-243, https://doi.org/10.1175/1520-0442-12.1.230.
Giorgi, F., J. W. Hurrell, M. R. Marinucci, and M. Beniston, 1997: Elevation dependency of the surface climate change signal: A model study. J. Climate, 10, 288-296, https://doi.org/10.1175/ 1520-0442(1997)010<0288:EDOTSC $>2.0 . C O ; 2$.

Gottfried, M., and Coauthors, 2012: Continent-wide response of mountain vegetation to climate change. Nat. Climate Change, 2, 111-115, https://doi.org/10.1038/nclimate1329.

Guo, D., E. Yu, and H. Wang, 2016: Will the Tibetan Plateau warming depend on elevation in the future? J. Geophys. Res. Atmos., 121, 3969-3978, https://doi.org/10.1002/2016JD024871.

Hall, A., 2004: The role of surface albedo feedback in climate. J. Climate, 17, 1550-1568, https://doi.org/10.1175/1520-0442(2004)017<1550: TROSAF $>2.0 . \mathrm{CO} ; 2$.

Hong, S.-Y., Y. Noh, and J. Dudhia, 2006: A new vertical diffusion package with an explicit treatment of entrainment processes. Mon. Wea. Rev., 134, 2318-2341, https://doi.org/10.1175/ MWR3199.1.

Ikeda, K., and Coauthors, 2010: Simulation of seasonal snowfall over Colorado. Atmos. Res., 97, 462-477, https://doi.org/ 10.1016/j.atmosres.2010.04.010.

Im, E.-S., E. Coppola, F. Giorgi, and X. Bi, 2010: Local effects of climate change over the Alpine region: A study with a high resolution regional climate model with a surrogate climate change scenario. Geophys. Res. Lett., 37, L05704, https://doi.org/ 10.1029/2009GL041801.

Janjić, Z. I., 1994: The step-mountain eta coordinate model: Further developments of the convection, viscous sublayer, and turbulence closure schemes. Mon. Wea. Rev., 122, 927-945, https://doi.org/10.1175/1520-0493(1994)122<0927: TSMECM $>2.0 . \mathrm{CO} ; 2$.

Jiang, D., Y. Zhang, and X. Lang, 2011: Vegetation feedback under future global warming. Theor. Appl. Climatol., 106, 211-227, https://doi.org/10.1007/s00704-011-0428-6.

Kotlarski, S., T. Bosshard, D. Lüthi, P. Pall, and C. Schär, 2012: Elevation gradients of European climate change in the regional climate model COSMO-CLM. Climatic Change, 112, 189-215, https://doi.org/10.1007/s10584-011-0195-5.

, D. Lüthi, and C. Schär, 2015: The elevation dependency of 21st century European climate change: An RCM ensemble perspective. Int. J. Climatol., 35, 3902-3920, https://doi.org/ 10.1002/joc. 4254 .

Letcher, T. W., and J. R. Minder, 2015: Characterization of the simulated regional snow albedo feedback using a regional climate model over complex terrain. J. Climate, 28, 7576-7595, https://doi.org/10.1175/JCLI-D-15-0166.1.

Liu, C., K. Ikeda, G. Thompson, R. Rasmussen, and J. Dudhia, 2011: High-resolution simulations of wintertime precipitation in the Colorado Headwaters region: Sensitivity to physics parameterizations. Mon. Wea. Rev., 139, 3533-3553, https:// doi.org/10.1175/MWR-D-11-00009.1.

, and Coauthors, 2017: Continental-scale convection-permitting modeling of the current and future climate of North America. Climate Dyn., 49, 71-95, https://doi.org.10.1007/s00382-016-3327-9.

Liu, X., Z. Cheng, L. Yan, and Z.-Y. Yin, 2009: Elevation dependency of recent and future minimum surface air temperature trends in the Tibetan Plateau and its surroundings. Global Planet. Change, 68, 164-174, https://doi.org/10.1016/ j.gloplacha.2009.03.017.

Loranty, M. M., L. T. Berner, S. J. Goetz, Y. Jin, and J. T. Randerson, 2014: Vegetation controls on northern high latitude snow-albedo feedback: Observations and CMIP5 model simulations. Global Change Biol., 20, 594-606, https:// doi.org/10.1111/gcb.12391. 
Mesinger, F., and Coauthors, 2006: North American Regional Reanalysis. Bull. Amer. Meteor. Soc., 87, 343-360, https://doi.org/ 10.1175/BAMS-87-3-343.

Minder, J. R., T. W. Letcher, and S. M. Skiles, 2016: An evaluation of high-resolution regional climate model simulations of snow cover and albedo over the Rocky Mountains, with implications for the simulated snow-albedo feedback. J. Geophys. Res. Atmos., 121, 9069-9088, https://doi.org/ 10.1002/2016JD024995.

Niu, G.-Y., and Z.-L. Yang, 2007: An observation-based formulation of snow cover fraction and its evaluation over large North American river basins. J. Geophys. Res., 112, D21101, https:// doi.org/10.1029/2007JD008674.

— , and Coauthors, 2011: The community Noah land surface model with multiparameterization options (Noah-MP): 1. Model description and evaluation with local-scale measurements. J. Geophys. Res., 116, D12109, https://doi.org/10.1029/ 2010JD015139.

Oyler, J. W., S. Z. Dobrowski, A. P. Ballantyne, A. E. Klene, and S. W. Running, 2015: Artificial amplification of warming trends across the mountains of the western United States. Geophys. Res. Lett., 42, 153-161, https://doi.org/10.1002/ 2014 GL062803.

Painter, T. H., K. Rittger, C. McKenzie, P. Slaughter, R. E. Davis, and J. Dozier, 2009: Retrieval of subpixel snow covered area, grain size, and albedo from MODIS. Remote Sens. Environ., 113, 868-879, https://doi.org/10.1016/j.rse.2009.01.001.

Palazzi, E., L. Filippi, and J. von Hardenberg, 2017: Insights into elevation-dependent warming in the Tibetan PlateauHimalayas from CMIP5 model simulations. Climate Dyn., 48, 3991-4008, https://doi.org/10.1007/s00382-016-3316-z.

Pepin, N., and J. Lundquist, 2008: Temperature trends at high elevations: Patterns across the globe. Geophys. Res. Lett., 35, L14701, https://doi.org/10.1029/2008GL034026.

_- and Coauthors, 2015: Elevation-dependent warming in mountain regions of the world. Nat. Climate Change, 5, 424430, https://doi.org/10.1038/nclimate2563.

Rangwala, I., 2013: Amplified water vapour feedback at high altitudes during winter. Int. J. Climatol., 33, 897-903, https:// doi.org/10.1002/joc.3477.

_ J. R. Miller, and M. Xu, 2009: Warming in the Tibetan Plateau: Possible influences of the changes in surface water vapor. Geophys. Res. Lett., 36, L06703, https://doi.org/10.1029/ 2009GL037245.

, — - G. L. Russell, and M. Xu, 2010: Using a global climate model to evaluate the influences of water vapor, snow cover and atmospheric aerosol on warming in the Tibetan Plateau during the twenty-first century. Climate Dyn., 34, 859-872, https://doi.org/10.1007/s00382-009-0564-1.

_ _ J. Barsugli, K. Cozzetto, J. Neff, and J. Prairie, 2012: Mid-21st century projections in temperature extremes in the southern Colorado Rocky Mountains from regional climate models. Climate Dyn., 39, 1823-1840, https://doi.org/10.1007/s00382-011-1282-z.

—, E. Sinsky, and J. R. Miller, 2013: Amplified warming projections for high altitude regions of the Northern Hemisphere mid-latitudes from CMIP5 models. Environ. Res. Lett., 8, 024040, https://doi.org/10.1088/1748-9326/8/2/024040.

,-- , and,- 2016 : Variability in projected elevation dependent warming in boreal midlatitude winter in CMIP5 climate models and its potential drivers. Climate Dyn., 46, 2115-2122, https://doi.org/10.1007/s00382-015-2692-0.

Rasmussen, R., and Coauthors, 2011: High-resolution coupled climate runoff simulations of seasonal snowfall over Colorado:
A process study of current and warmer climate. J. Climate, $\mathbf{2 4}$ 3015-3048, https://doi.org/10.1175/2010JCLI3985.1.

_ , and Coauthors, 2014: Climate change impacts on the water balance of the Colorado Headwaters: High-resolution regional climate model simulations. J. Hydrometeor., 15, 10911116, https://doi.org/10.1175/JHM-D-13-0118.1.

Rhoades, A. M., P. A. Ullrich, and C. M. Zarzycki, 2018: Projecting 21st century snowpack trends in western USA mountains using variable-resolution CESM. Climate Dyn., 50, 261-288, https://doi.org/10.1007/s00382-017-3606-0.

Rupp, D. E., S. Li, P. W. Mote, K. M. Shell, N. Massey, S. N. Sparrow, D. C. H. Wallom, and M. R. Allen, 2017: Seasonal spatial patterns of projected anthropogenic warming in complex terrain: A modeling study of the western US. Climate Dyn., 48, 2191-2213, https://doi.org/10.1007/s00382-016-3200-x.

Salathé, E. P., Jr., R. Steed, C. F. Mass, and P. H. Zahn, 2008: A highresolution climate model for the U.S. Pacific Northwest: Mesoscale feedbacks and local responses to climate change. J. Climate, 21, 5708-5726, https://doi.org/10.1175/2008JCLI2090.1.

Schär, C., C. Frei, D. Lüthi, and H. C. Davies, 1996: Surrogate climate-change scenarios for regional climate models. Geophys. Res. Lett., 23, 669-672, https://doi.org/10.1029/ 96GL00265.

Skamarock, W. C., and Coauthors, 2008: A description of the Advanced Research WRF version 3. NCAR Tech. Note NCAR/TN-475+STR, 113 pp., http://dx.doi.org/10.5065/ D68S4MVH.

Thackeray, C. W., C. G. Fletcher, and C. Derksen, 2015: Quantifying the skill of CMIP5 models in simulating seasonal albedo and snow cover evolution. J. Geophys. Res. Atmos., 120, 58315849, https://doi.org/10.1002/2015JD023325.

Thompson, G., P. R. Field, R. M. Rasmussen, and W. D. Hall, 2008: Explicit forecasts of winter precipitation using an improved bulk microphysics scheme. Part II: Implementation of a new snow parameterization. Mon. Wea. Rev., 136, 5095-5115, https://doi.org/10.1175/2008MWR2387.1.

Viviroli, D., and Coauthors, 2011: Climate change and mountain water resources: Overview and recommendations for research, management and policy. Hydrol. Earth Syst. Sci., 15, 471-504, https://doi.org/10.5194/hess-15-471-2011.

Vuille, M., E. Franquist, R. Garreaud, W. S. Lavado Casimiro, and B. Cáceres, 2015: Impact of the global warming hiatus on Andean temperature. J. Geophys. Res. Atmos., 120, 37453757, https://doi.org/10.1002/2015JD023126.

Walton, D. B., F. Sun, A. Hall, and S. Capps, 2015: A hybrid dynamical-statistical downscaling technique. Part I: Development and validation of the technique. J. Climate, 28, 45974617, https://doi.org/10.1175/JCLI-D-14-00196.1.

—, A. Hall, N. Berg, M. Schwartz, and F. Sun, 2017: Incorporating snow albedo feedback into downscaled temperature and snow cover projections for California's Sierra Nevada. J. Climate, 30, 1417-1438, https://doi.org/10.1175/ JCLI-D-16-0168.1.

Wang, L., J. N. S. Cole, P. Bartlett, D. Verseghy, C. Derksen, R. Brown, and K. von Salzen, 2016: Investigating the spread in surface albedo for snow-covered forests in CMIP5 models. J. Geophys. Res. Atmos., 121, 1104-1119, https://doi.org/ 10.1002/2015JD023824.

Wang, Q., X. Fan, and M. Wang, 2014: Recent warming amplification over high elevation regions across the globe. Climate Dyn., 43, 87-101, https://doi.org/10.1007/s00382-013-1889-3.

Winter, K. J.-P. M., S. Kotlarski, S. C. Scherrer, and C. Schär, 2017: The Alpine snow-albedo feedback in regional climate 
models. Climate Dyn., 48, 1109-1124, https://doi.org/10.1007/ s00382-016-3130-7.

Yan, L., Z. Liu, G. Chen, J. E. Kutzbach, and X. Liu, 2016: Mechanisms of elevation-dependent warming over the Tibetan Plateau in quadrupled $\mathrm{CO}_{2}$ experiments. Climatic Change, $\mathbf{1 3 5}$, 509-519, https://doi.org/10.1007/s10584-016-1599-z.

You, Q., S. Kang, N. Pepin, W.-A. Flügel, Y. Yan, H. Behrawan, and J. Huang, 2010: Relationship between temperature trend magnitude, elevation and mean temperature in the Tibetan Plateau from homogenized surface stations and reanalysis data. Global Planet. Change, 71, 124-133, https://doi.org/ 10.1016/j.gloplacha.2010.01.020.

Zeng, Z., and Coauthors, 2015: Regional air pollution brightening reverses the greenhouse gases induced warming-elevation relationship. Geophys. Res. Lett., 42, 4563-4572, https://doi.org/ 10.1002/2015GL064410. 